\title{
أثر استخدام إستراتيجية تعليم الأقران على إتقان المهارات الفنية لدى طلاب قسم التربية الفنية بكلية التربية النوعية
}

\author{
إعداد

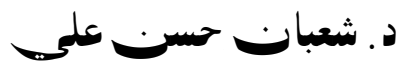 \\ مدرس علم نفس التربية الفنية \\ كلية التربية النوعية - جامعة جنوب الوادي لهربية
}

مجلة بحوث التربية النوعية ـ جامعة المنصورة

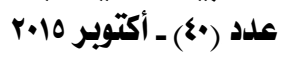




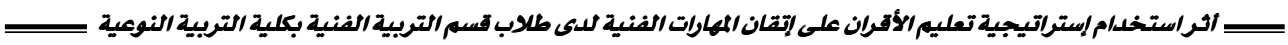




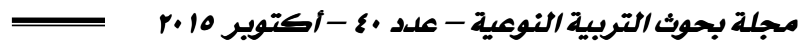

أثر استخدام إستراتيجية تعليم الأقران على إتقان المهارات الفنيية

لدى طلاب قسم التزبية الفنية بكلية التربية النوعية

إعداد

د . شعبازخسن:عليح

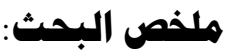

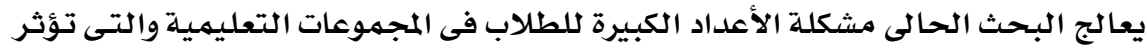

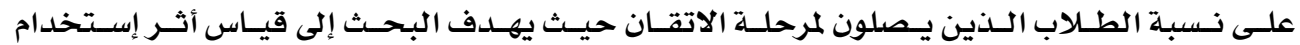

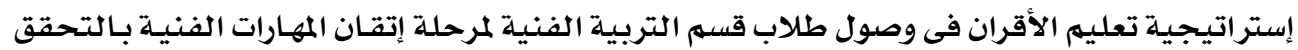
من الفرضين التاليين :-

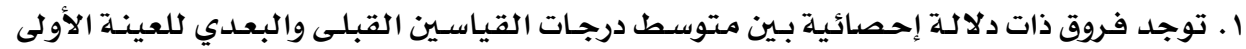

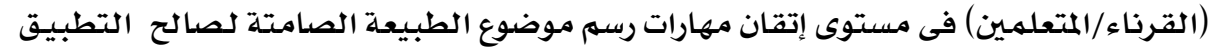

البعدى.

r. توجد فروق ذات دلالة إحصائية بين متوسط درجـات القياسـين القبلى والبعـدي للعينـة الثانيـة

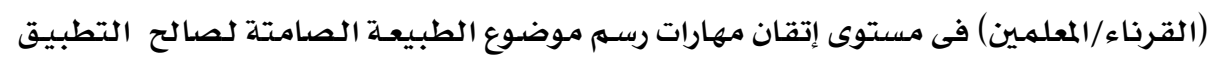

البعدى.

وبلغت العينة (rا) من طلاب الفرقة الاولى بقسمى التربية الفنية مقسمـين إلى (ابم) قرين

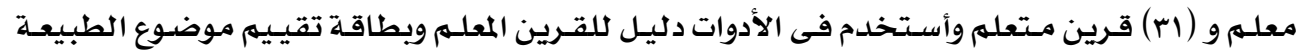

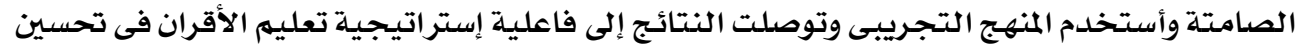

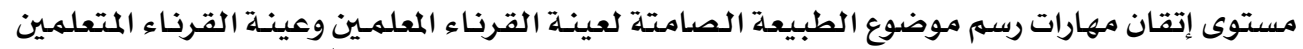

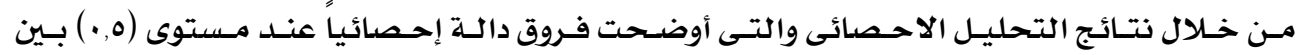

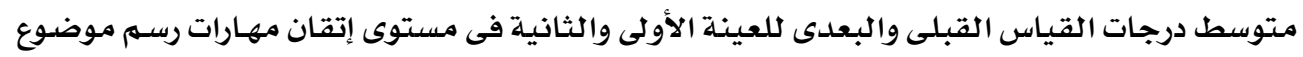

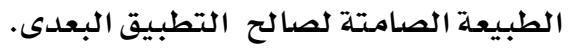

همبدمبة

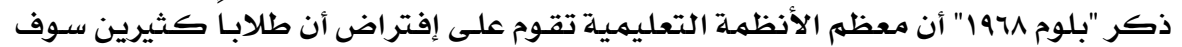

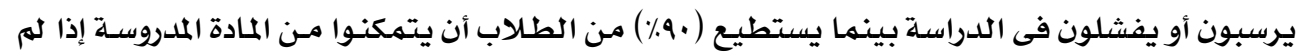

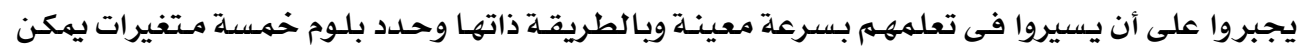

"مدرس علم نفس التربية الفنية - كلية التربية النوعية - جامعة جنوب الوادي 
التحكم بها للسماح لكل متعلهم بأن يتمكن من تعلمـه هى الإستعداد، نوعية التدريس، القدرة على فهـم

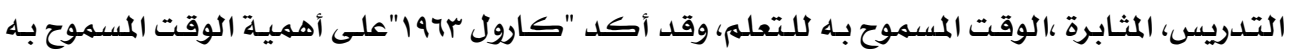

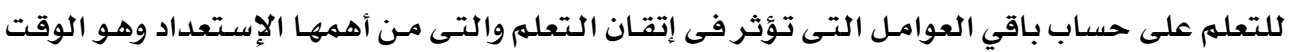

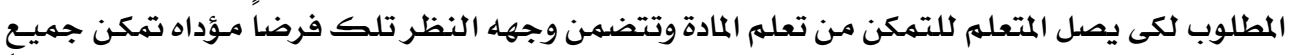

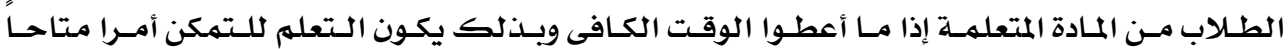

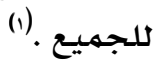
وقد رسخت أراء كاءلا من "كارول باج1" و"بلوم 1971" لإستر اتيجية إتقان التعلم والتى تقوم

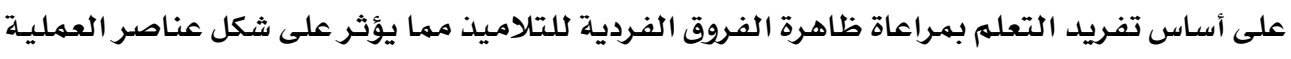

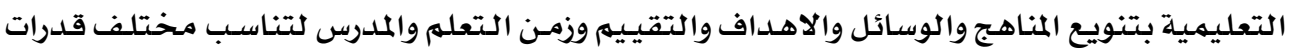

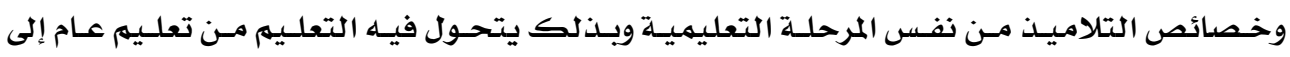

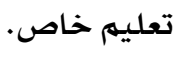
كما ترتبط إستراتيجية تفريد التعليهم بواقع ممارسات التعليم الجماعي وإجراءات التعليم

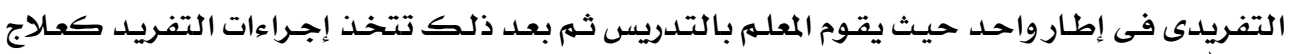

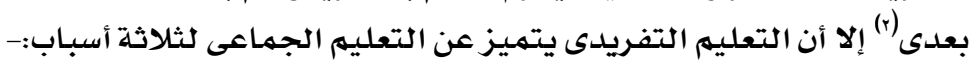

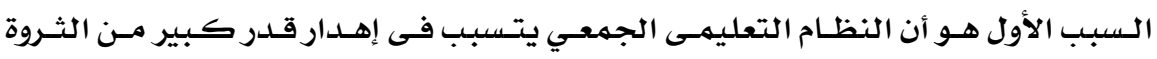

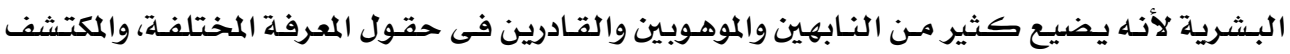

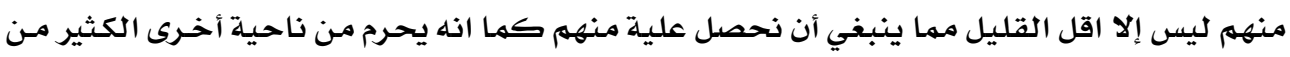

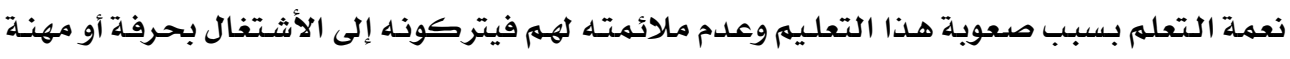

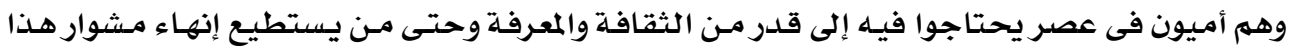

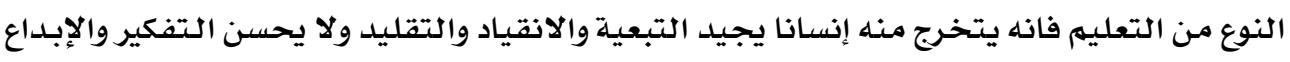

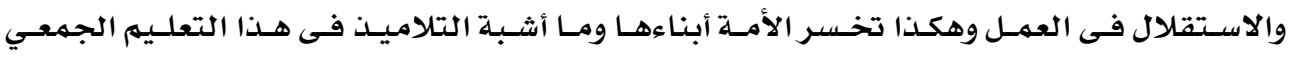

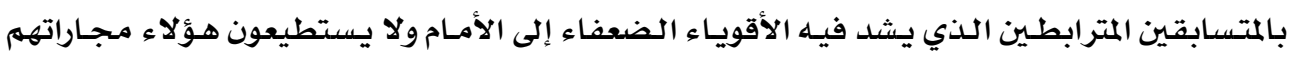

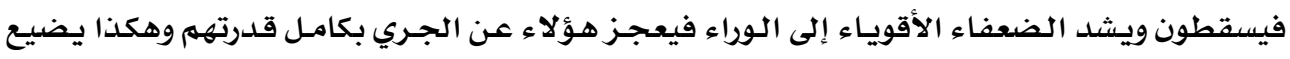

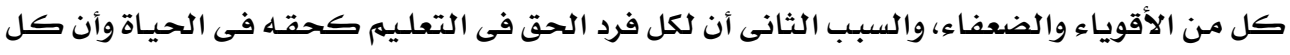

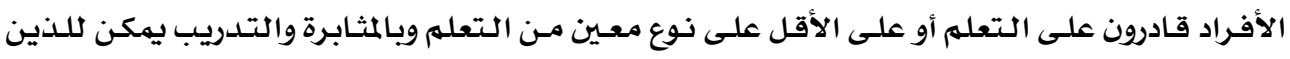

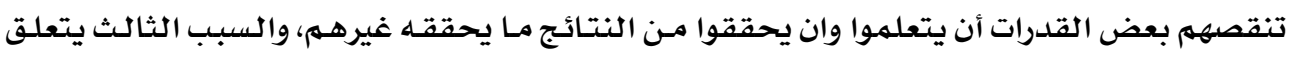

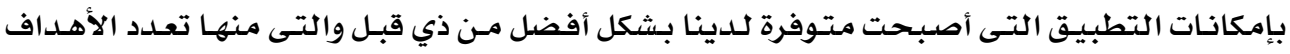

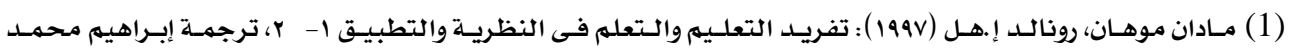

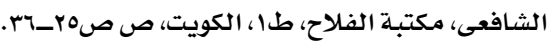

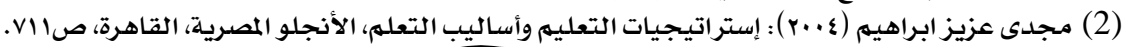


وتمكننا من تصنيفها وتحليلها ووضـع المنـاهج الدراسيـة بالمستويات والنوعيـات المختلفـة وتوفير الكتب

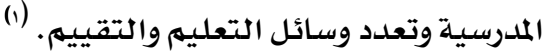

وفى مقابل تلك المميزات للتعلهم التفريدى والتى من أهمها أنه يرسيخ لمفهوم التعلم للاتقان التهان

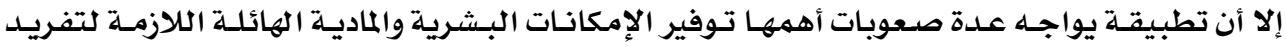

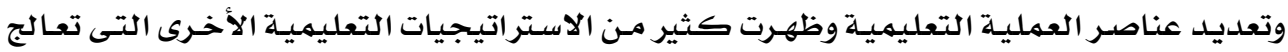

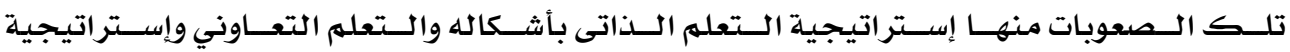
تعليم الأقران.

حيث يعد التعليم بالأقران من أهم الإستراتيجيات الحديثة المستخدمة في تحقيق الأهـداف

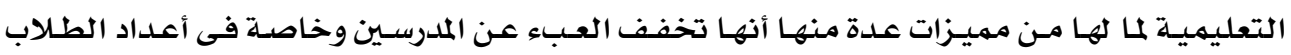

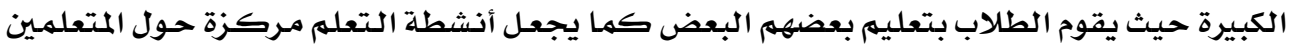

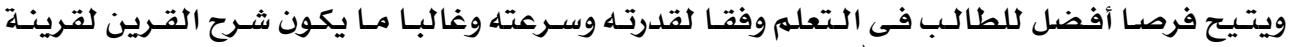

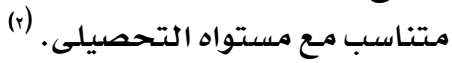

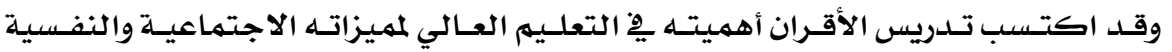

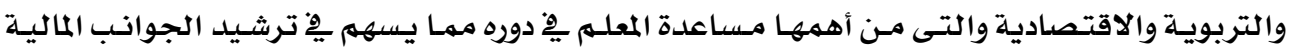

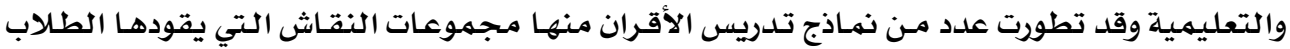

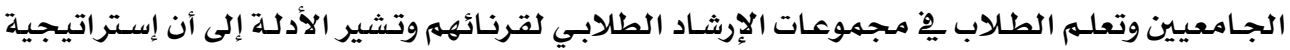

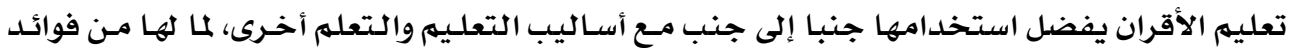

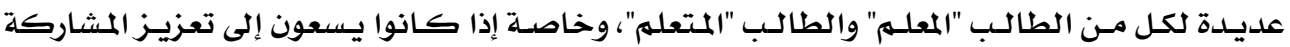

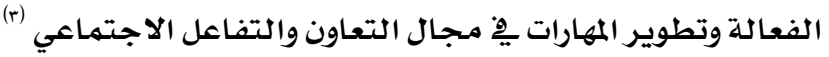

لاحظ الباحثث أثنـاء عملـه بـالكنترول حصول نسبة قليلـة مـن طلاب قسهم التربيـة الفنيـة

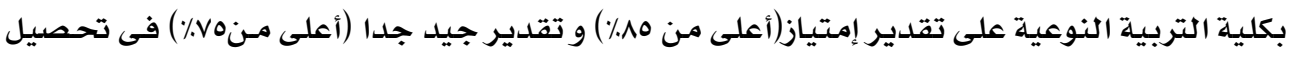

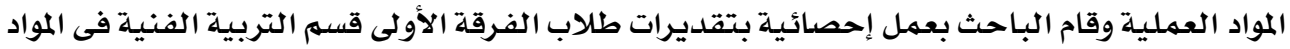

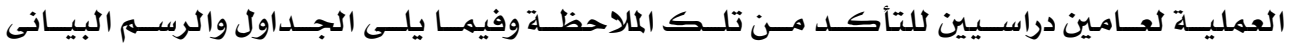


جدول(1) (1) (1) (1)

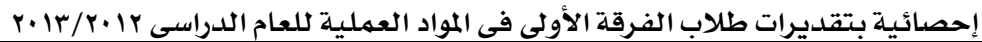

\begin{tabular}{|c|c|c|c|c|c|c|c|c|c|c|}
\hline \multicolumn{2}{|c|}{ راسب } & \multicolumn{2}{|c|}{ مقبول } & \multicolumn{2}{|c|}{ جيد } & \multicolumn{2}{|c|}{ جيد جدا } & \multicolumn{2}{|c|}{ مثتاز } & \\
\hline النسبة & العلد & النسبة & العلد & النسبة & العلدد & النسبة & العلدد & النسبة & العلدد & \\
\hline$\Lambda, \zeta$ & r. & 09,9 & $I \leqslant Y$ & 10,7 & $r v$ & $9, r$ & rr & 7,1 & 17 & رسيم \\
\hline 0,9 & 17 & 07 & lor & $1 \varepsilon, r$ & rq & $\vee, \vee$ & $r$ & $r, q$ & $\wedge$ & نحت(1) \\
\hline 1,1 & $r$ & $\xi \xi, \bigvee$ & IrY & $r \wedge, q$ & va & $\xi, \xi$ & ir & 1,1 & $r$ & تصميم(1) \\
\hline 1,1 & 0 & $0 \xi, q$ & 10. & 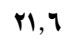 & 09 & 0,1 & $1 \varepsilon$ & $r, r$ & 9 & أشفال فنية(1) \\
\hline $1, \wedge$ & 0 & $\xi \xi, \bigvee$ & Irr & $r \cdot, 0$ & 07 & $i r, \Lambda$ & ro & $\checkmark$ & 19 & نسيج يدوى(1) \\
\hline
\end{tabular}

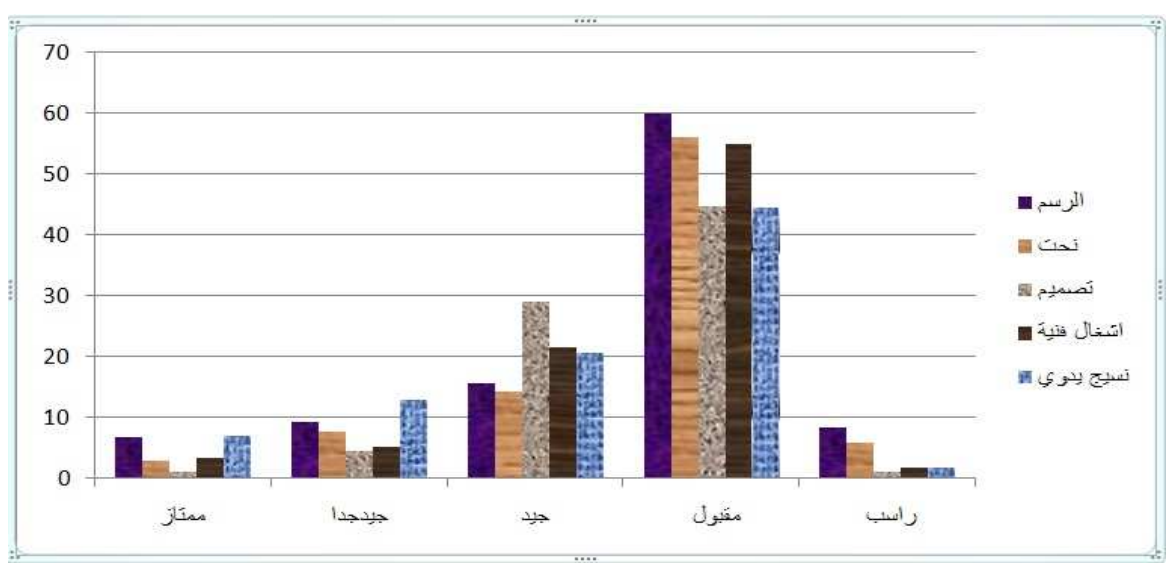

شكل(1)

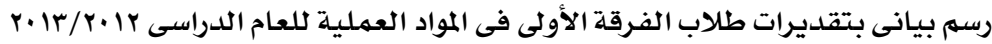

جدول(r)

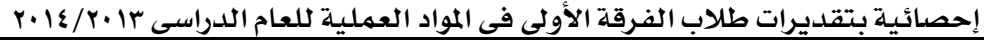

\begin{tabular}{|c|c|c|c|c|c|c|c|c|c|c|}
\hline \multicolumn{2}{|c|}{ راسب } & \multicolumn{2}{|c|}{ مقبول } & \multicolumn{2}{|c|}{ جيد } & \multicolumn{2}{|c|}{ جيد جدا } & \multicolumn{2}{|c|}{ مثتاز } & \\
\hline النسبة & العلد & النسبة & العدد & النسبة & العلدد & النسبة & العدد & النسبة & العلد & \\
\hline - & - & $\Delta \Delta, Y$ & $1 \cdot r$ & Ir, & ro & $r$ r, & $\$ 1$ & $\Lambda, r$ & 10 & رسم \\
\hline - & - & $V 乏, r$ & 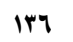 & Ir, & ro & $\wedge, \vee$ & 17 & $r, r$ & $y$ & نحت(1) \\
\hline$\cdot, 0$ & 1 & $r q, q$ & vr & $r q, 1$ & 77 & $19, Y$ & rq & $r, \Lambda$ & v & تصميه(1) \\
\hline$r, r$ & $\varepsilon$ & $M r, \Lambda$ & 110 & rr, & $\$ 1$ & $\Lambda, r$ & 10 & $\xi, \xi$ & $\Lambda$ & أشفال فنية(1) \\
\hline$r, r$ & $\xi$ & Ir, 7 & rr & $r, v$ & $\Delta \Lambda$ & rA, r & v. & $10, r$ & $r \wedge$ & نسيج يلدوى(ا) \\
\hline
\end{tabular}




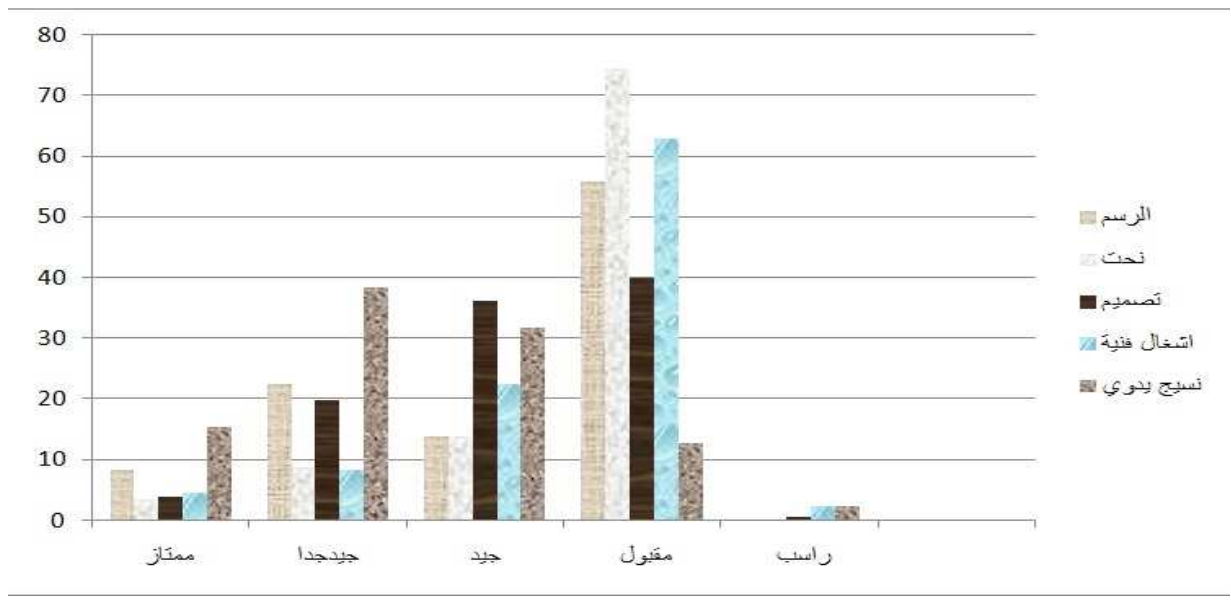

شكل(r)

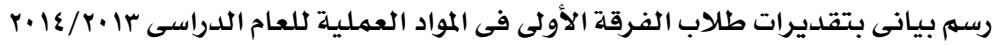

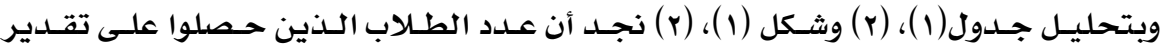

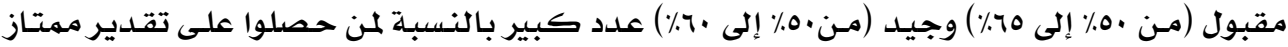

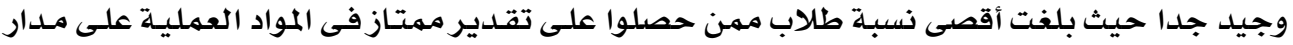

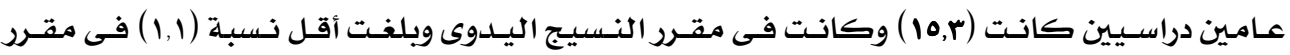

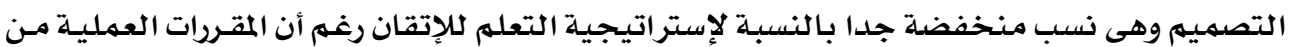
النوع الذي يجب الوصول فى اكتسابها إلى محسك الإتقـان والـذى يتصف بالسـرعة والدقة ومـن هـذه

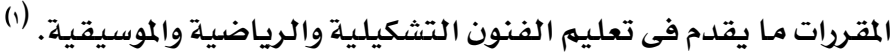

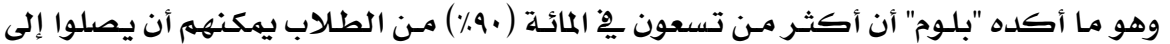

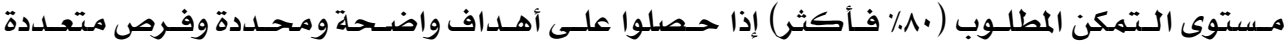

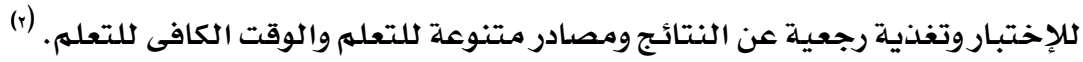
وقد إفترض الباحث إستنادا إلى أسس نظريات التعليم والتعلهم وسيكولوجية التعلم لإِتقان عدد من العوامل التى تؤدى إلى تلك المت المثكلة هى:

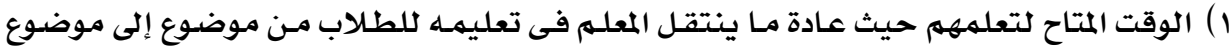

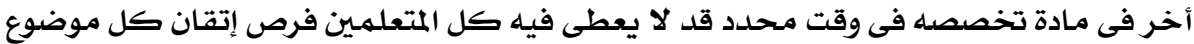

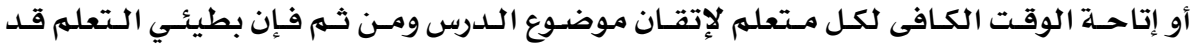




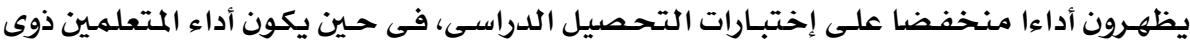

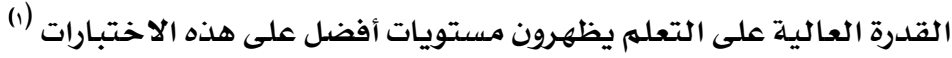

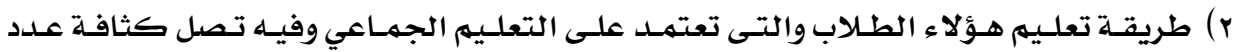

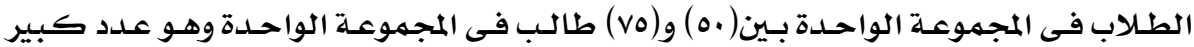

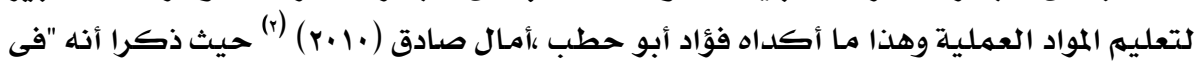

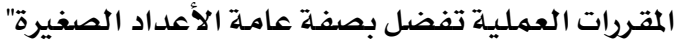

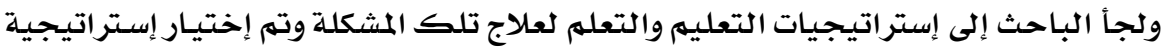

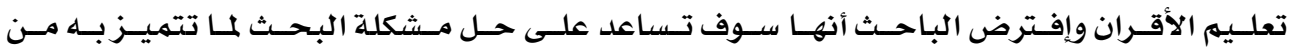

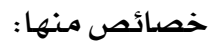

1) تناسـب خطوات إسـتراتيجيـة تعلسيه الأقـران في تحقيـق مميـزات سـيكولوجية التعلم لإإتقـان

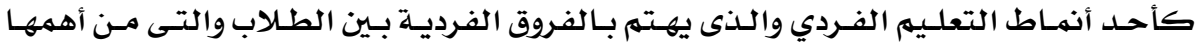

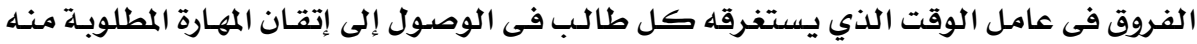

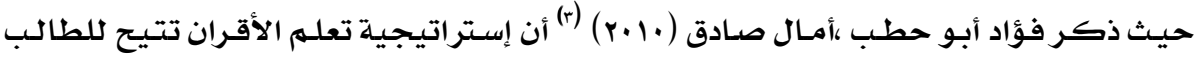

الوقت الضروري للوصول للمستوى المحلدد للإتقان.

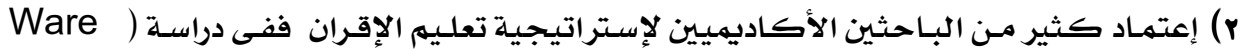

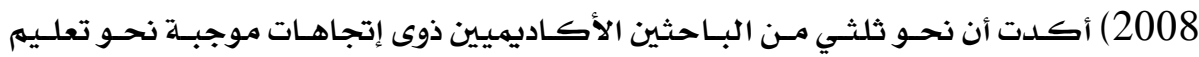

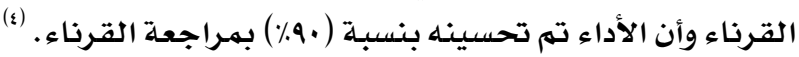

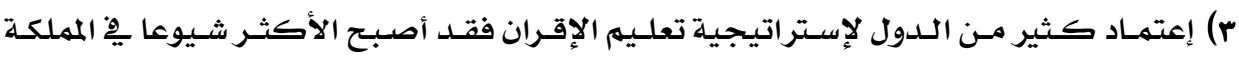

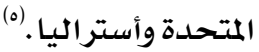

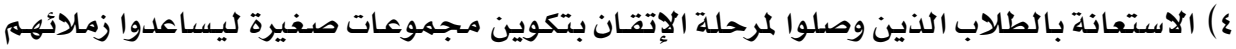

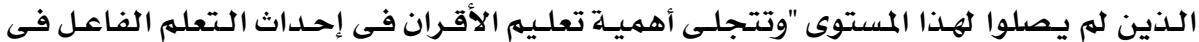

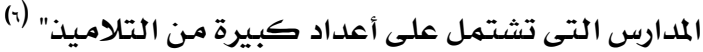

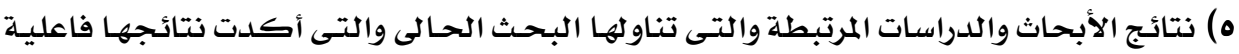

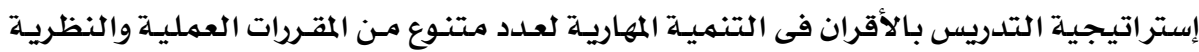

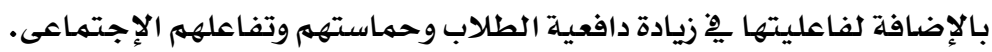

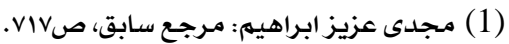

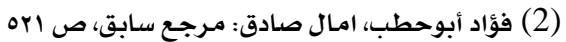

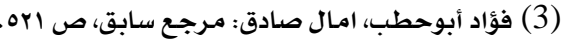

(4)Sachs, J., \& Parsell, M. (2013). , Op.Cit , p 14

(5)Sachs, J., \& Parsell, M. (2013). Peer review of learning and teaching in higher education: international perspectives (Vol. 9). Springer Science \& Business Media , p 17

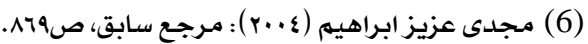




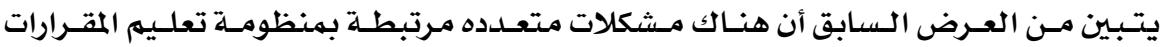

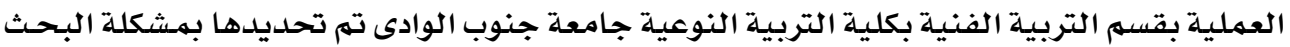

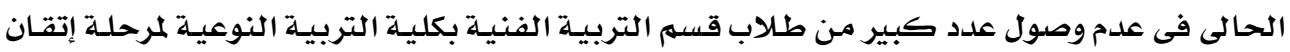

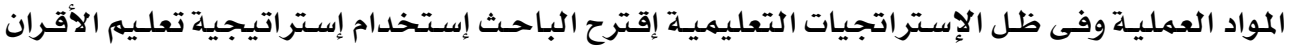

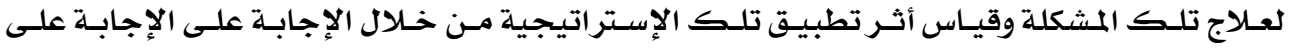

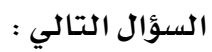

مـا أثر إستخدام إستراتيجية تعليهم الأقران في إتقان طلاب قسهم التربيـة الفنيـة للمهارات الفنية والتى تم تحديدها بثلاث مهارات مستهدفة بأحد المقرارات العملية وهو مقرر الرسئم.

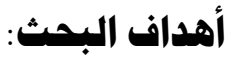

1) التعرف على أثر إستخدام إستراتيجية تعليهم الأقران يْ إتقان العينة الأولى (القرناء المتعلمين)

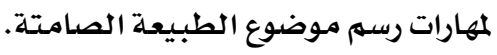

r) التعرف على أثر إستخدام إستراتيجية تعليه الأقران هِّ إتقان العينة الثانية (القرناء المعلمـين)

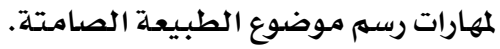

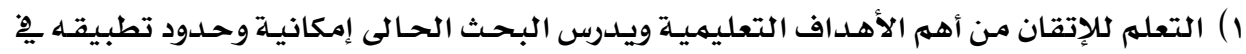

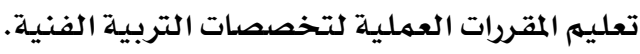

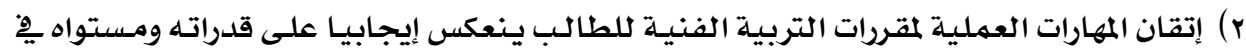

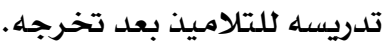

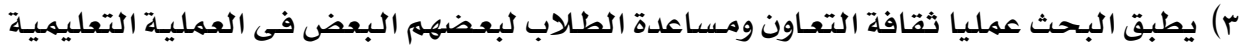

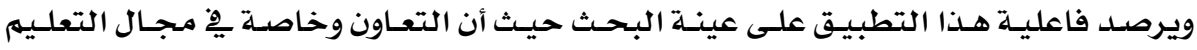

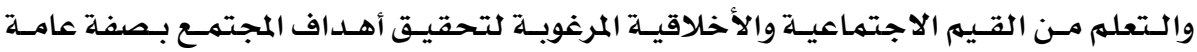

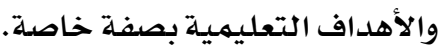

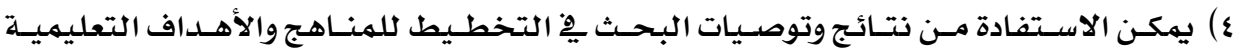

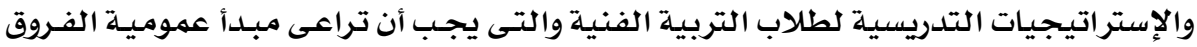

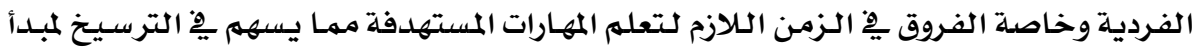

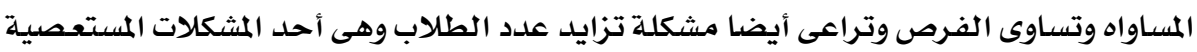

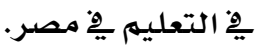

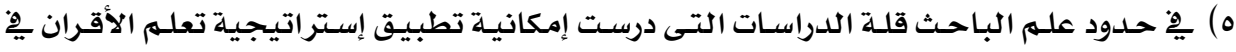
التعله لإاتتقان لطلاب التربية الفنية. 


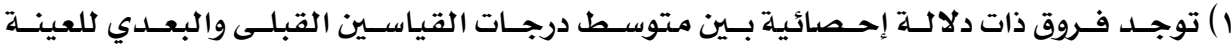

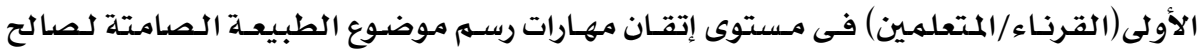

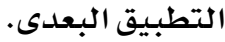

r) توجد فروق ذات دلالة إحصائية بـين متوسط درجـات القياسـين القبلى والبعـدي للعينـة الثانيـة

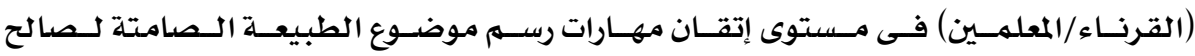

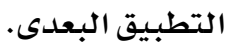

هدود البمث:

1) حدود بشرية: (rا7) طالب وطالبـة بالفرقة الأولى قسم التربية الفنية.

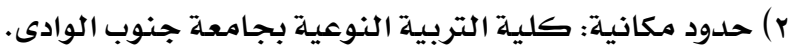

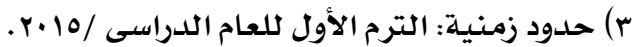

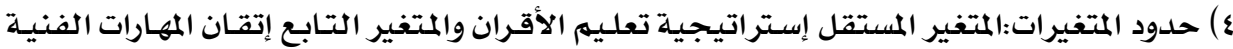

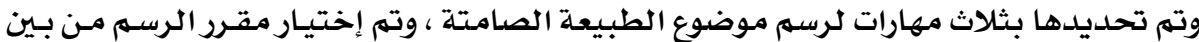

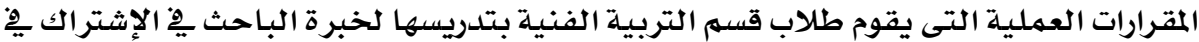

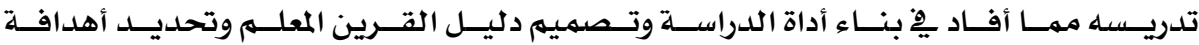
ووسائل تنفيذة.

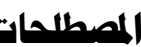

$$
\text { تُعرف مصطلحات البحث إجرائياً كما يلي :- ألعات }
$$

• الأثر: التغير الذي يمكن أن تحدثه إسـتراتيجية تدريس الأقران فى وصـول طلاب قسم التربيـة

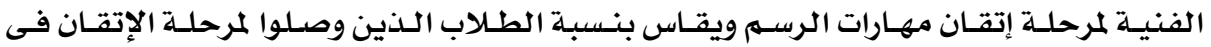

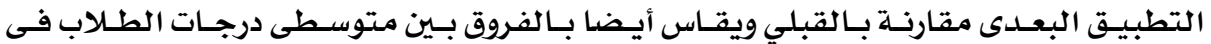

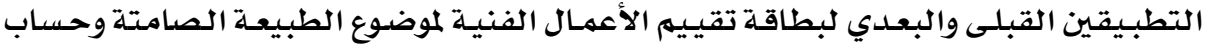

$$
\text { حجم التأثير. }
$$

• الإستراتيجية: إجراءات وخطوات تنفيذ تعليم الأقران المتبعة في البحث.

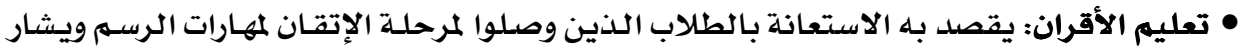

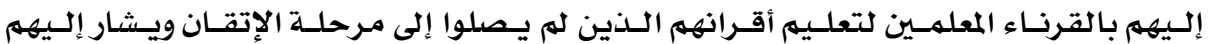

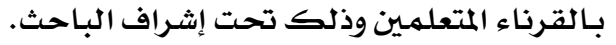

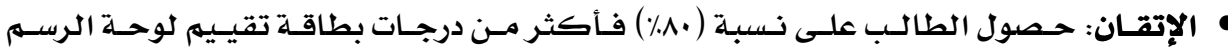
وموضوعها الطبيعة الصامتة. • المهارات الفنية: الأهداف المهاريـة المراد تحقيقها من رسئم موضـوع الطبيعـة الصـامتتة وهى مهارة رسم النسب ومهارة رسم التكوين ومهارة التظليل. وأتخذ الباحث عدة إجراءات لتحقيق أهداف البحث هى :- 
المحور الأول: إستراتيجية تعليه الأقران:( مفهومها ـ أهميتها ـ أنواعها ـ العوامل المؤثرة ـ خطوات تطبيقها)

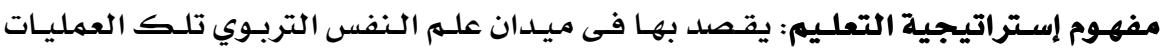

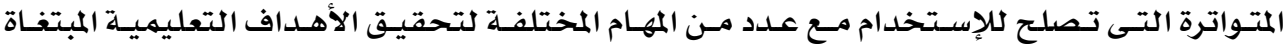

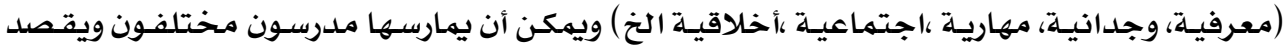

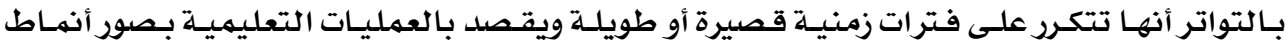

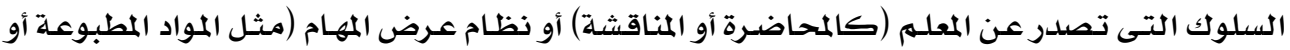

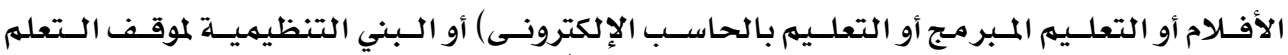

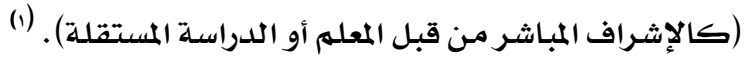

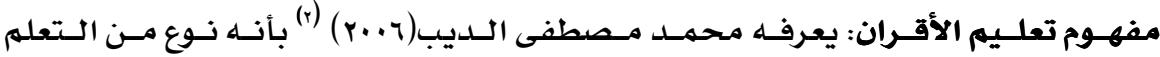

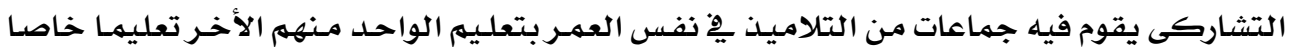

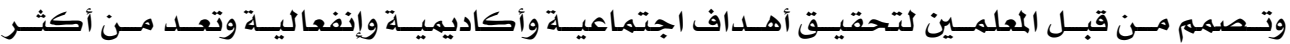

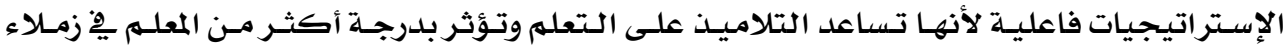

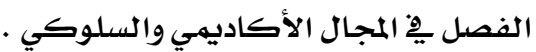

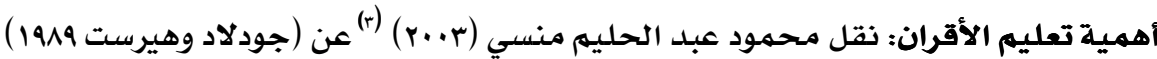

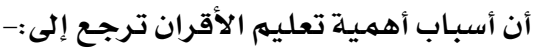

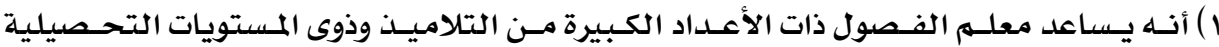
المتباينة على تحقيق أهداف التعله.

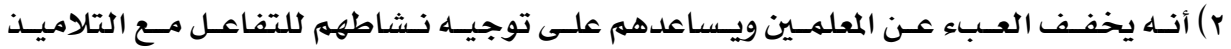

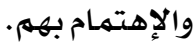

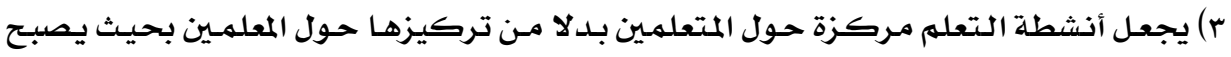

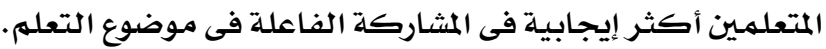

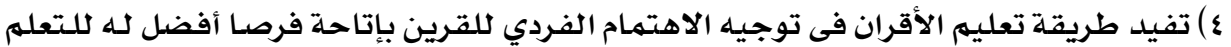

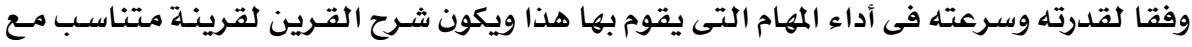

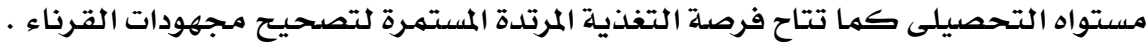

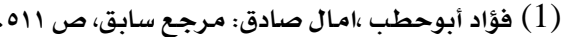

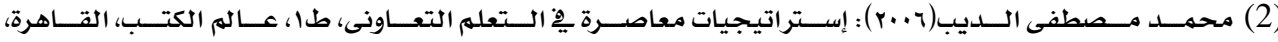




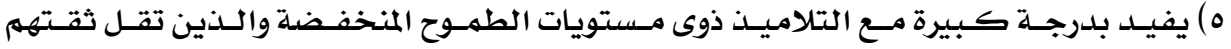

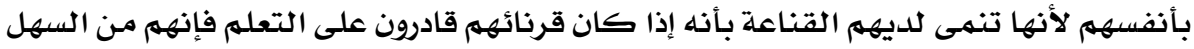
تعلههم أيضا.

7) تحسن من تعليم المضربين إنفعالياً لبناء الثقة والمهارات الاجتماعية لديهم.

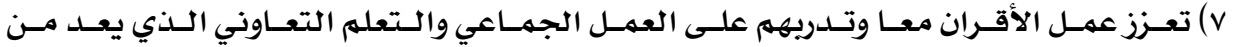

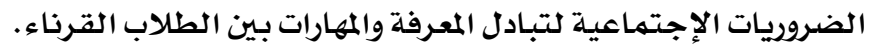

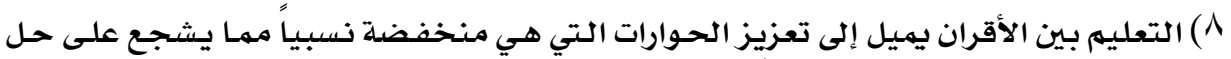

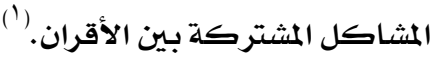

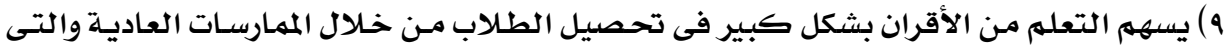

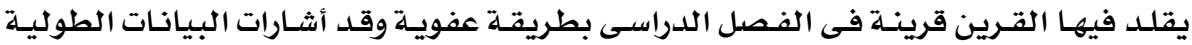

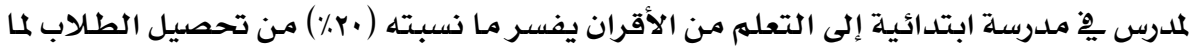

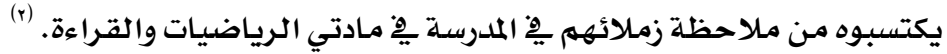

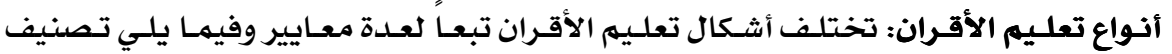

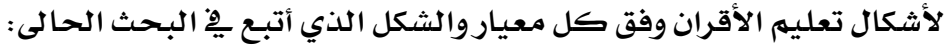
جدول (r)

تصنيف لأشكال تعليم الأقران وفق كل معيار والشكل الذي أتبع بِِ البحث الحالى

\begin{tabular}{|c|c|c|c|c|c|c|c|c|c|c|}
\hline \multicolumn{2}{|c|}{ من حيث نوع التعليم } & \multicolumn{2}{|c|}{ من حيث نوع } & \multicolumn{2}{|c|}{ من حيث الأدوار } & \multicolumn{2}{|c|}{ من حيث عدد الأقران } & \multicolumn{2}{|c|}{ من حيث القرين المعلم / المتعلم } & \multirow{2}{*}{ المعيار } \\
\hline عز بعد & فردى خصوصي & تكميلي & كلى & ل دور تبادلي & إبت & مجموعة صفيرة & إثناز & أعمار مختلفة & نقس العمر & \\
\hline & $\sqrt{ }$ & $\sqrt{ }$ & & & $\sqrt{ }$ & & $\sqrt{ }$ & & $\sqrt{ }$ & الشكل المتبع \\
\hline
\end{tabular}

العوامل المؤثرة على التعلم بإستراتيجية التعلم بالأقران:

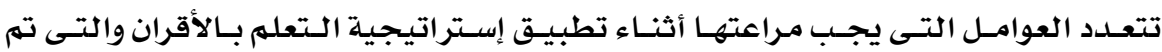

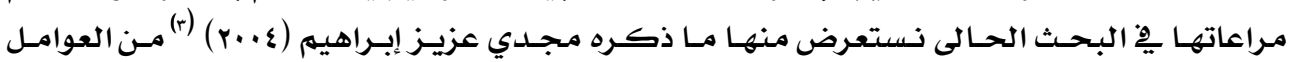

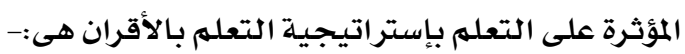

( ) جنس الأقران بحيث إذا كان الأقران من نفس الجنس فإن هذا ييسر عملية التعله.

(1)Damon, W., \& Phelps, E. (1989). Critical distinctions among three approaches to peer education. International journal of educational research, 13(1), 9-19

(2)Jackson, C. K., \& Bruegmann, E. (2009). Teaching students and teaching each other: The importance of peer learning for teachers (No. w15202). National Bureau of Economic Research.

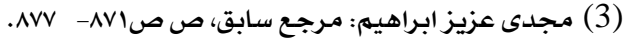


r) إذا كان الأقران من نفس المستوى الإجتماعي الثقايِّ فإن تعلم الأقران يكون أفضل منـة عندما تتباين هذه المستويات.

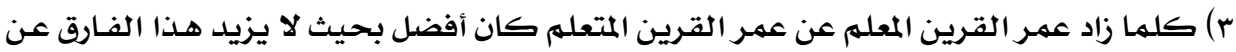

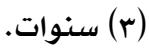
ع ) تزيد إمكانية تحقيق الأهداف كلما تكررت جلسات التعليم. ه) طول الجلسـة يتفاوت حسب طبيعة المادة والأهداف.

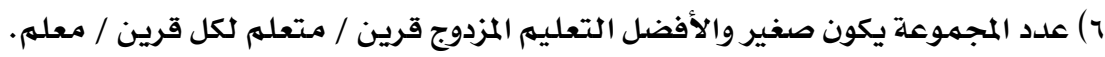

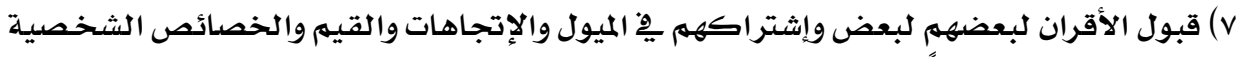

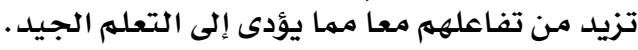

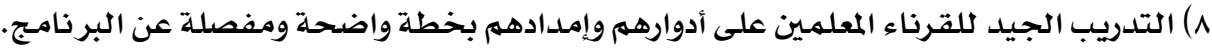

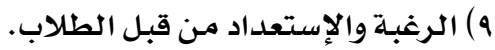

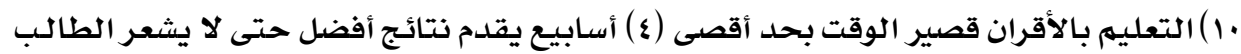

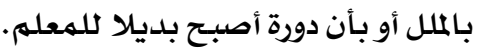

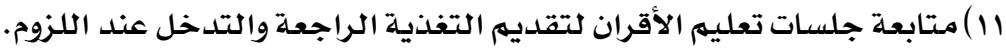

خطوات تطبيقها:

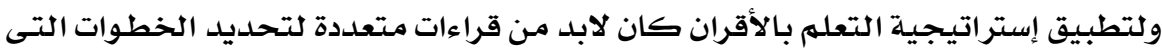

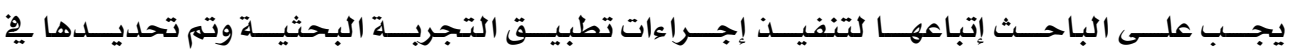
الخطوات التالية:-

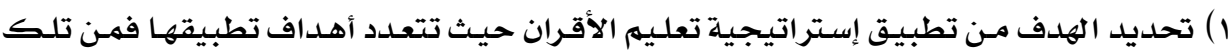

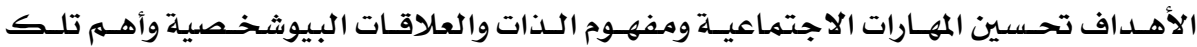

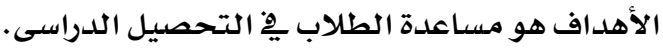

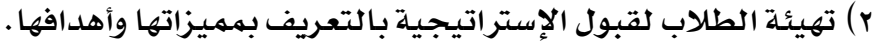

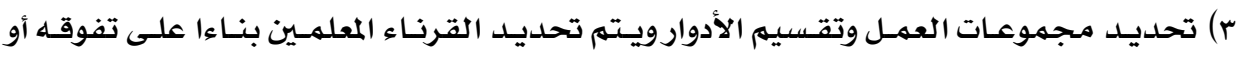

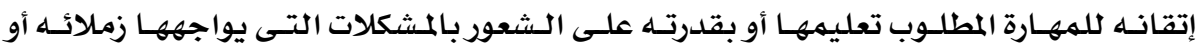
بالدافعية للقيام بدور القرين المعلم .

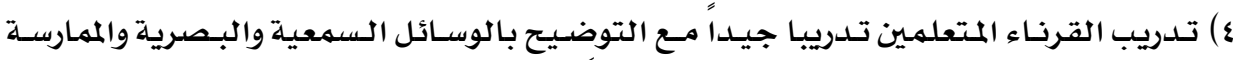

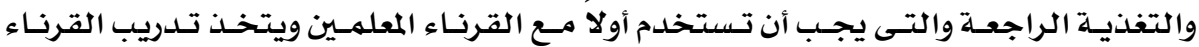

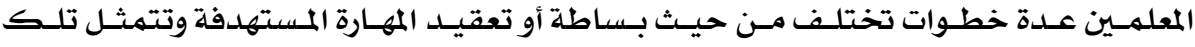

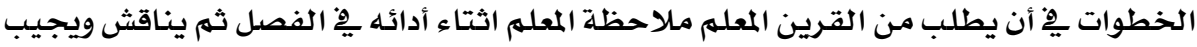

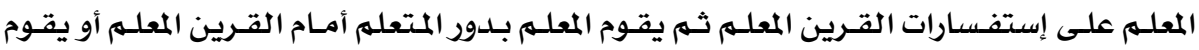
القرين المعله بأداء مـع احد القرناء المتعلمـين أمام المعلهم ثم يقيهم أدائه ويعلدل أخطائه.

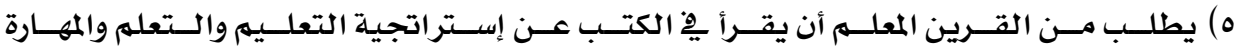


7) يقوم المعلم بإعداد كتيب بتعليمات تفصيلية لإجراءات الإستراتيجية التدريسية.

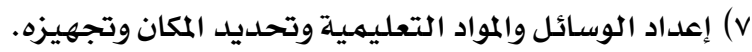

^) إعداد أدوات التقييه.

ه) التطبيق الفعلي لتعليهم الأقران.

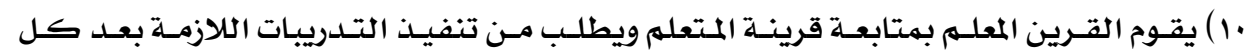

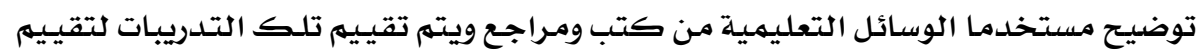

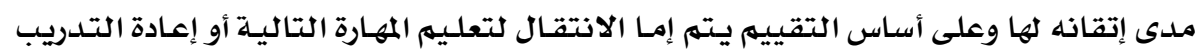

على المهارة نفسها.

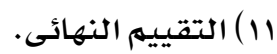

المحور الثانى: التعلم للإتقان ( ملدخل ـ مفهومه ـ أهميته ـ الأسس التى يستند إليها ـ إجراءاته)

مدخل:

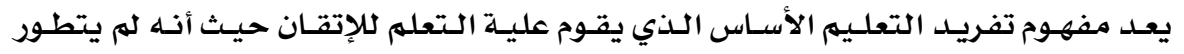

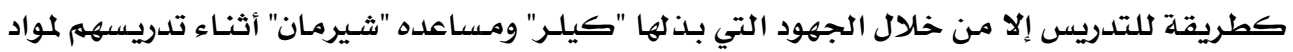

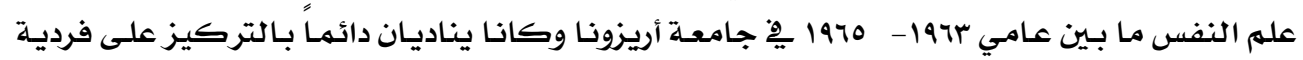

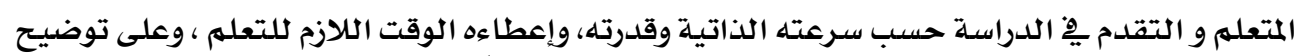

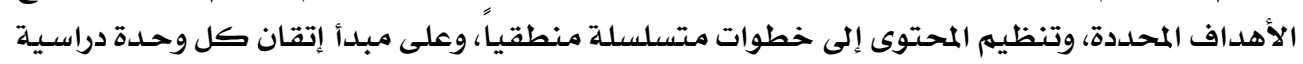

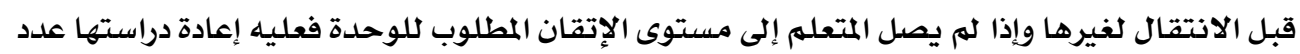

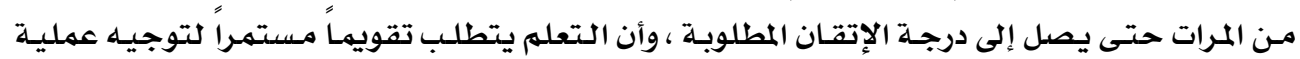

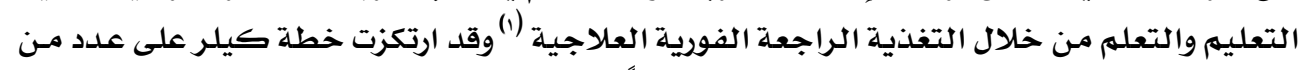

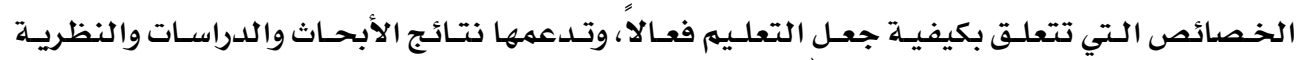

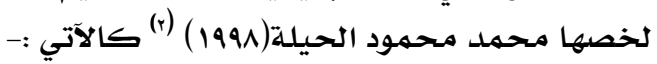

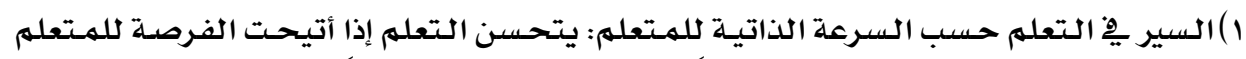

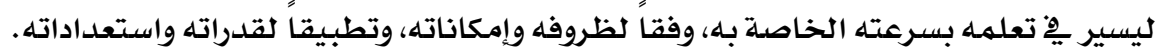

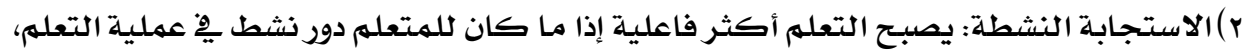
بحيث يستجيب لموضوع التعلهم، ويتفاعل معـه بنشاط.

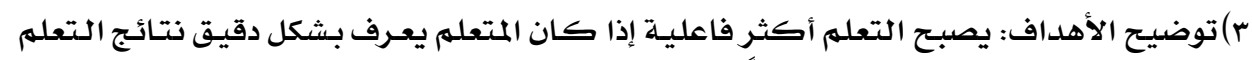

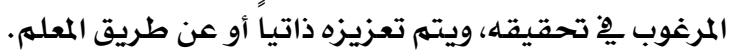

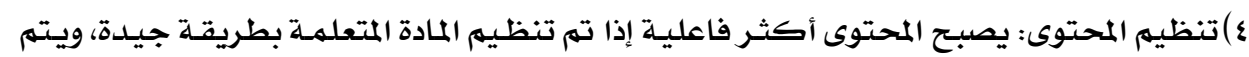

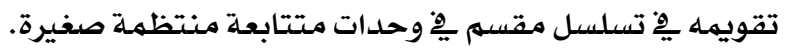

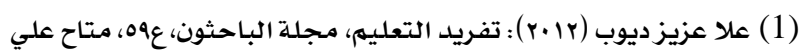

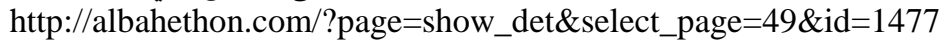
(2) علا عزيز ديوب: مرجع سابق. 


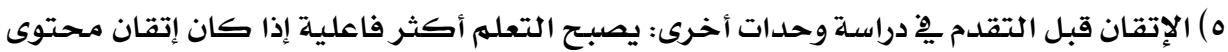

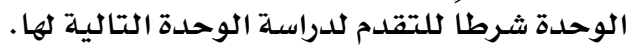

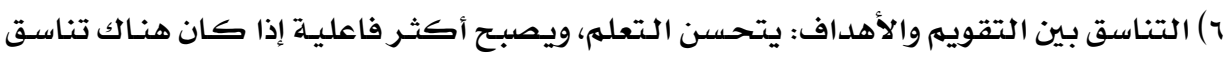

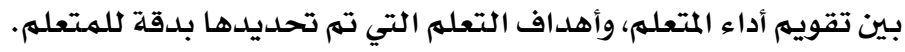

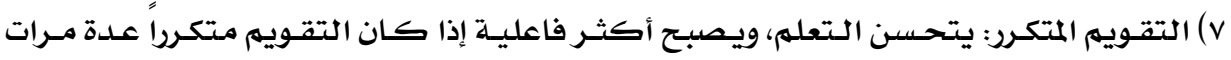

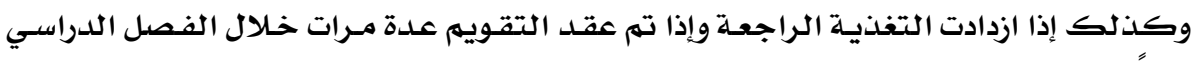

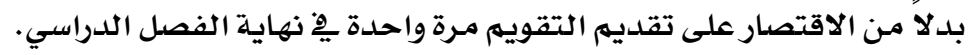

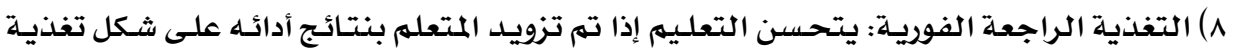

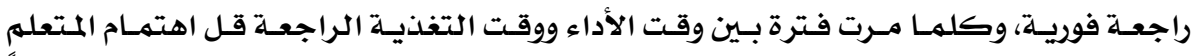

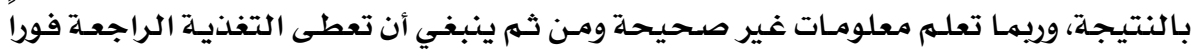
بمجرد الانتهاء من الأداء لتبصير المتعلمه بنتائج أدائة.

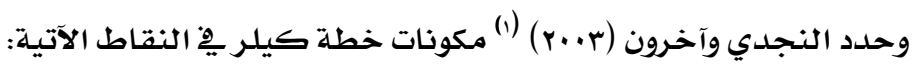

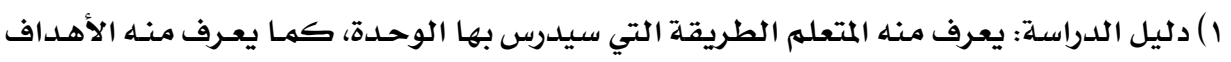

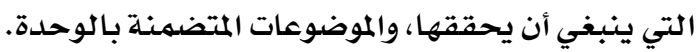

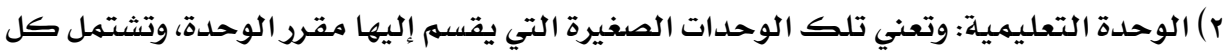

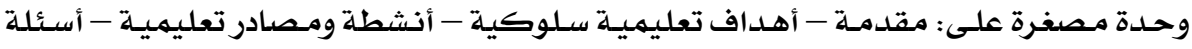

$$
\text { للتدريب والمراجعدة. }
$$

r) صحيفة المعلومات: وهي الكتيّب الذي يعد ليكون بديلاً أساسياً عن محتوى الوحدة الدراسية.

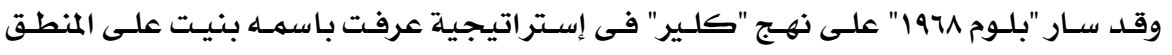

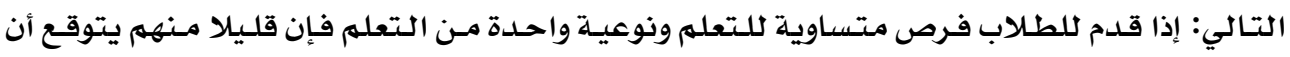

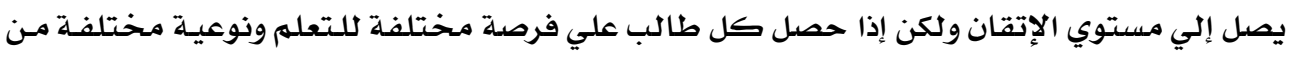

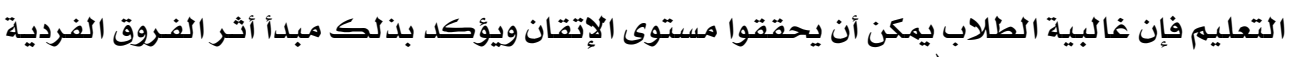

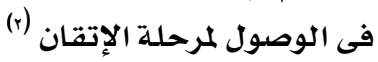

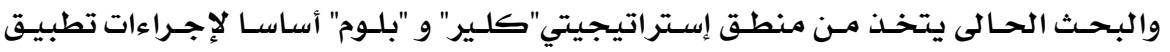

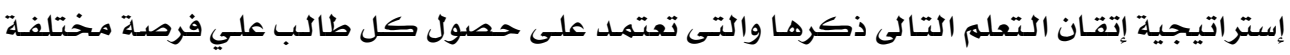

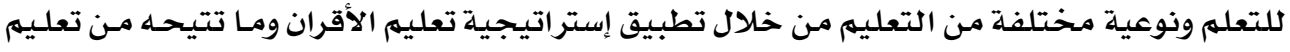

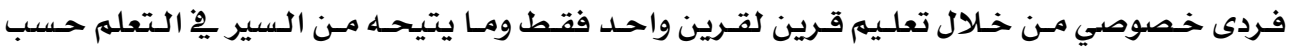

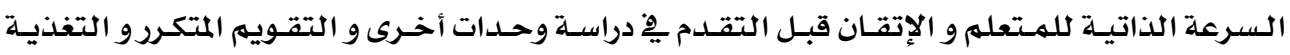

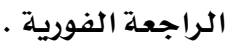


التعلم من أجل التمكن أو التعلم للإتقان مصطلحان مترادفان لمعنى واحد ومـن تعريفاته: هو مستوى يحدد مسبقا بصورة كمية يرجى أن يحققه كل فرد بعـد الانتهاء مـن عدد مـن أنساء

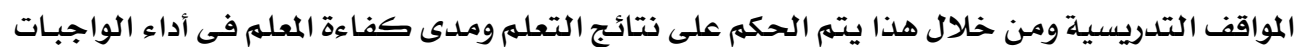
(1) المحددة له المبلد

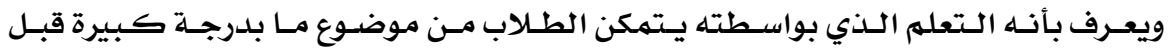

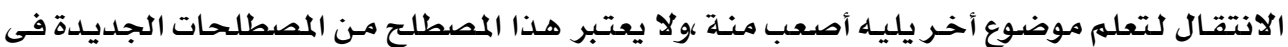
التربية بل بدأ فى الظهور منذ عام با719 على يد (كارول) الذي أهتهم بعنصر الوقت فى عمليـة التعلهم

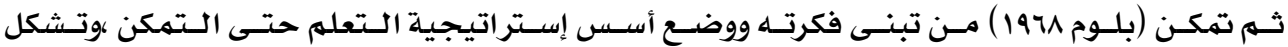

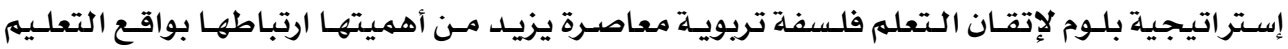

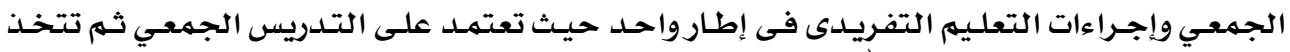
إجراءات التفريد كعلاج بعدى. (r)

واتخـذت هـذه السيكولوجية كأسـاس فلسفي للبحـث الحسالى حيـث طبـق التعلـيم الجمعـي

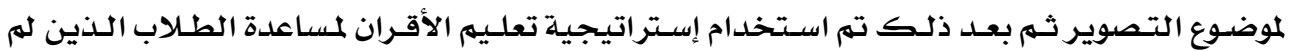

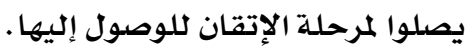
أهميته:

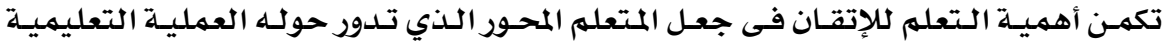

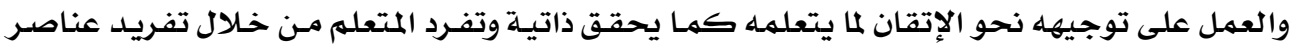

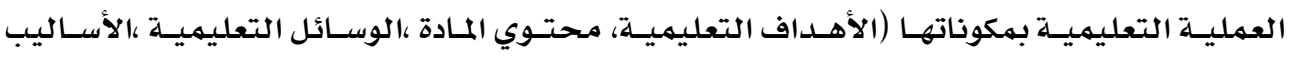

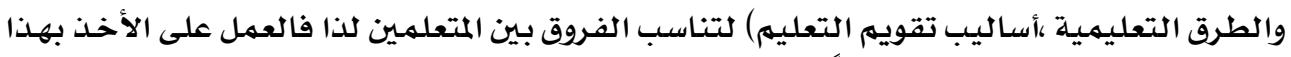

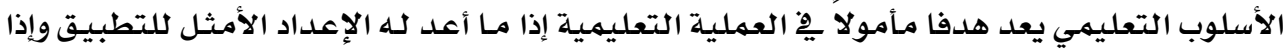

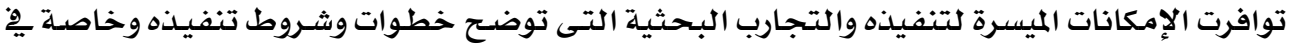

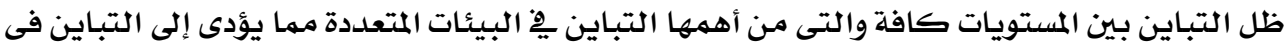

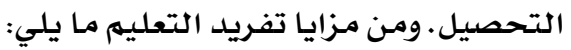
• تنمية مهارات الطلاب والاحتفاظ بالتعلهم وإنتقال أثره ِِّ المهارات والمواقف التعليمية المماثلة.

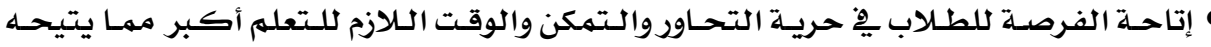
التدريس التقليدي.

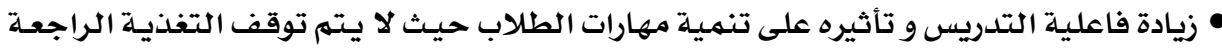

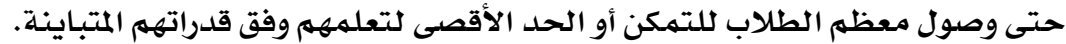

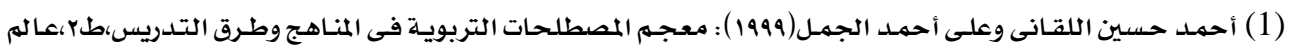

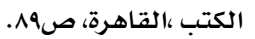

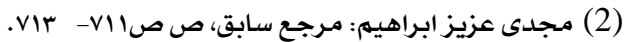


الأسس التى تستند إليها :

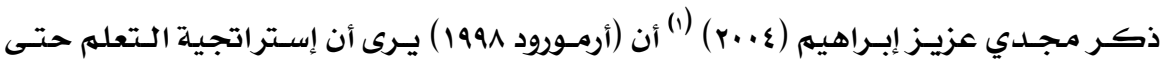

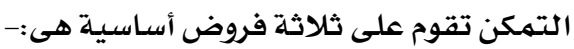

1) معظم الطلاب لديهم القدرة على التعلهم حتى التمكن.

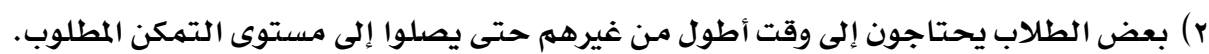

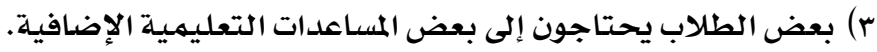

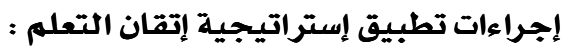

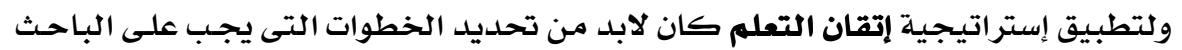

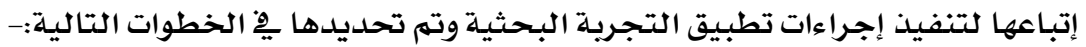

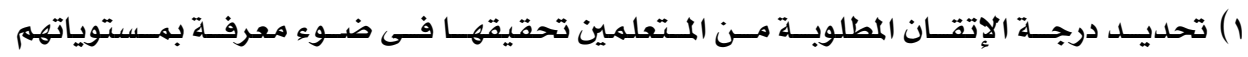
وخبر اتهم السابقة .

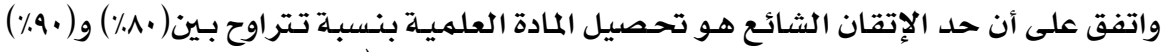

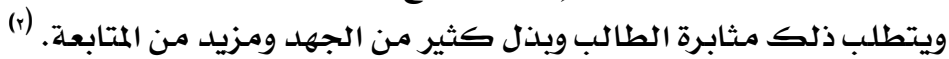

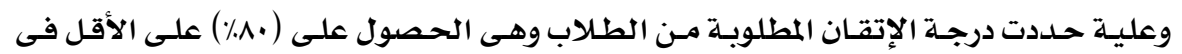

$$
\text { بطاقة تقييم اللوحة. }
$$

r) إعداد المادة موضوع التعلم وتنظيهها فى صورة وحدات صغيرة متتابعة محلددا تحديدا جيدا.

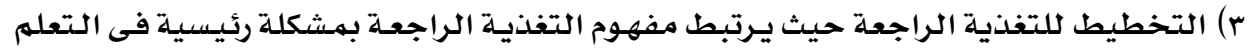

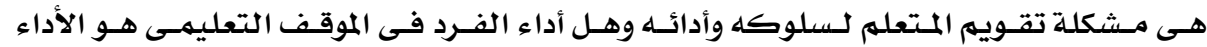

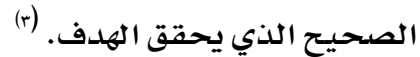

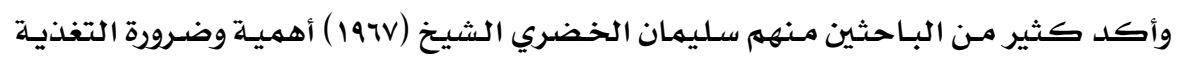

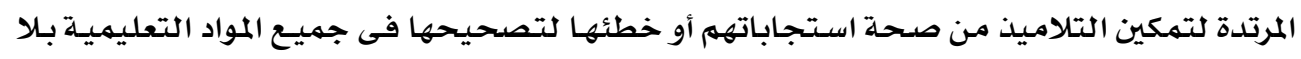

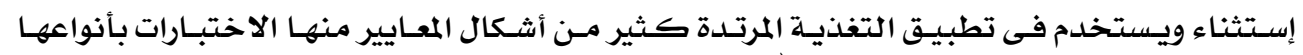

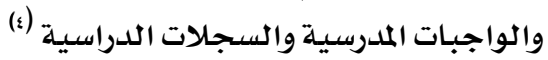

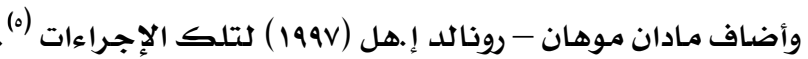
1) توفير مـرشد خاص لكل طالب.

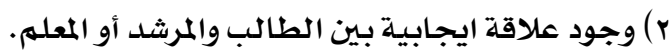

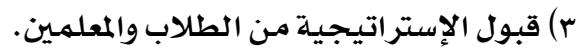
ع) الدافع الذاتى للتعلهم ومقدار المجهود المبذول من الطئل الطلاب.

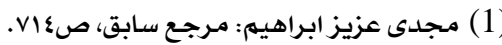

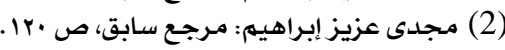

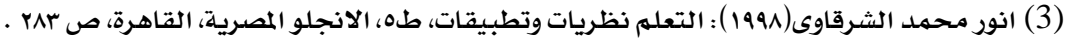

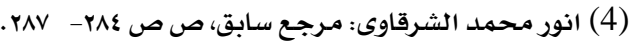

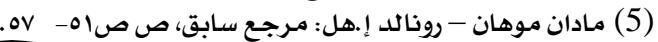


בب أثراستخدام إستراتيجية تعليم الأقران على إتقان المهارات الفنية للى طلاب قسم التريية الفنية بكلية التربية النوعية لــ ه) إتاحة الفرصدة للطلاب للتعلهم وفق قدراتهم وخطواتهم الخاصسة وتزويدهم بهسـارات مختلفـة أو اتجاهات دراسية مخختلفة تناسب المجموعات المختلفة من المتعلمـين .

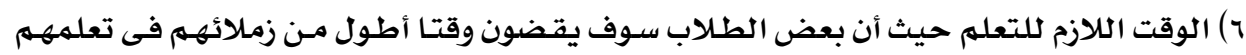
لمادة مـا. V) تحديد أهداف التدريس ومحتواه لكي نعلمه ما يتوقع من الطلاب والمدرسين .

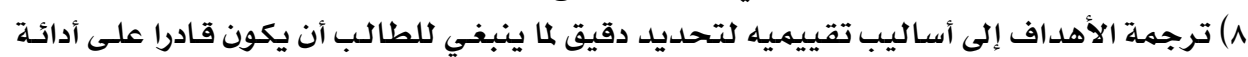

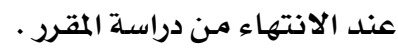
ه) إعداد معـايير ووسـائل التقيـيم التكويني لقيـاس مـدى التقدم الـذي أحسرزه الطلاب تجــاه تلـك المعايير لتحديد نواحي القوة والضعف وإعداد المواد الأسـاسية المساعدة والإضـافية على التتعلم

$$
\text { للعحلاج والإثراء. }
$$

• () الإستخدام المتكرر كلاختبـارات التقييمية التكوينية والذى تحلدد بـه سرعة التعلم ودفع الطلاب

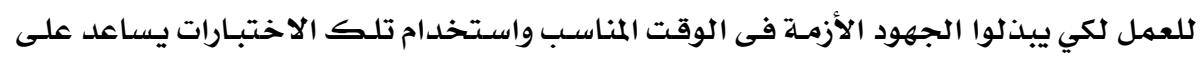

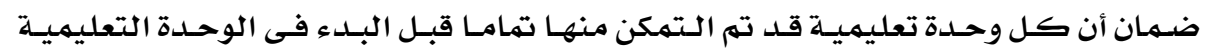

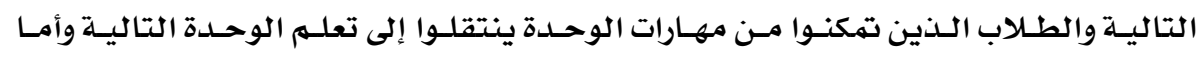
الطلاب الذين لم يصلوا إلى مستوى التمكن فى وحلدة معينة فان الاختبـارات التكوينيـة تحدد

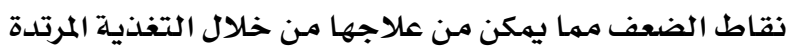
11) الاختبـارات التكوينيـة تشخص أيضا المنهج ووسائله. r) الاختبار التحصيلى النهائى. ويوضـح الشكل التخطيطي التالى الخطوات الإجـرائية لتطبيق إستراتيجية التعلهم للإِتقان

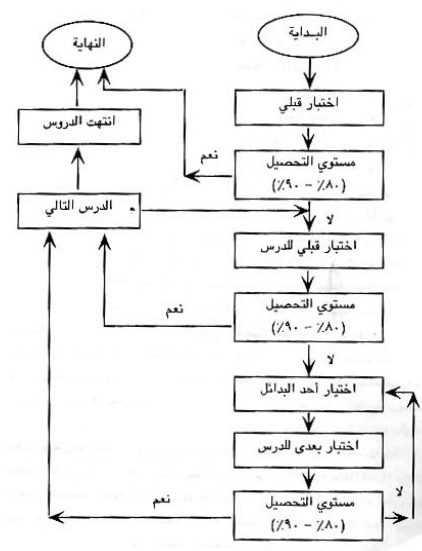

شكل (r)

الخطوات الإجـرائية لتطبيق إستراتيجية التعلم لإِتقان (1)

(1) مجدى عزيز ابراهيه: مرجـع سابق، صTIV. 
أولاً : الدراسات التى تناولت فاعلية إستراتيجية التعلم بالأقران في تنمية المهارات فى مجال التربية الفنية:

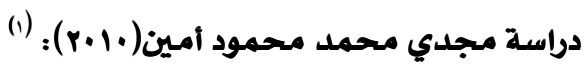

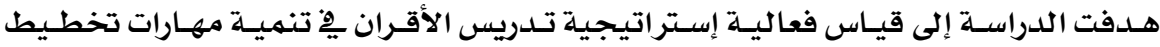

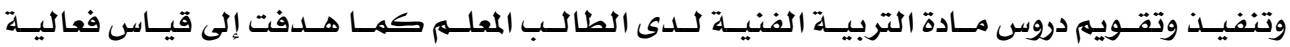

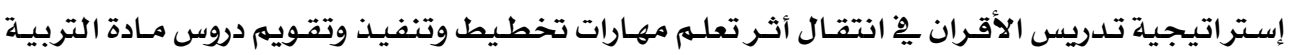

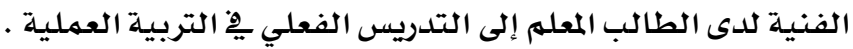

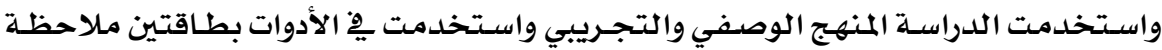

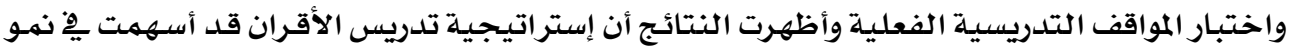

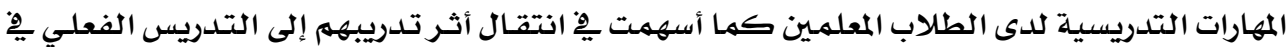
مدارس التربية العملي.

\section{دراسة إبراهيم السيد محمد عطية درويش (1999) : (Y)}

هـدفت الدراسـة إلى قيـاس فعاليـة إسـتراتيجيـة التـدريس بـالأقران يْ تنـميـة مهـارات صـياغة

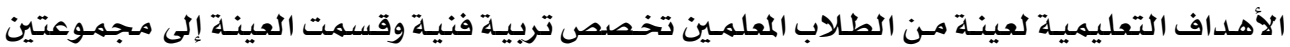

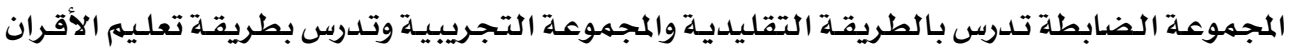

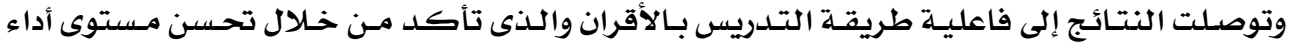

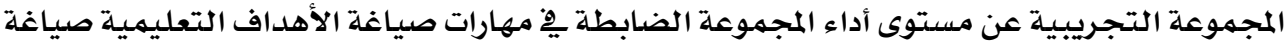

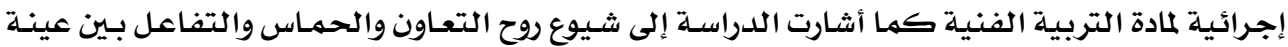

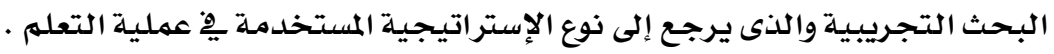

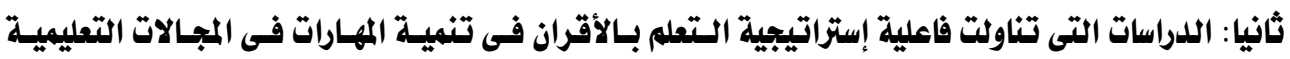

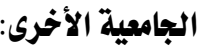

\section{دراسة عبير كمال محمد عثمان (r..v) (r.v)}

وهدفت إلى دراسـة اثر استخدام إستراتيجية التعلهم بـالأقران على تنميـة الأداء المهارى لعينـة

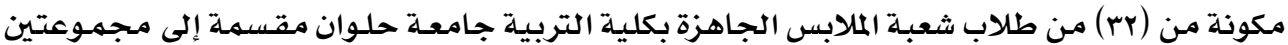

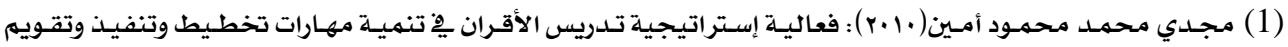

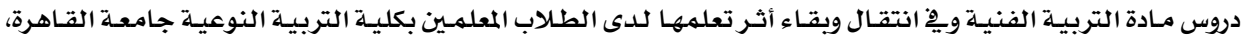

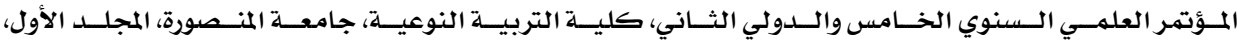
ص ص ص أlor

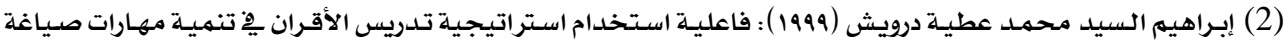

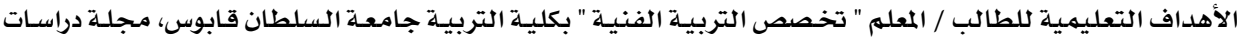

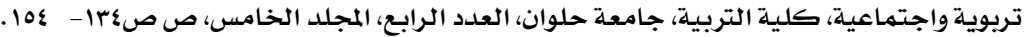

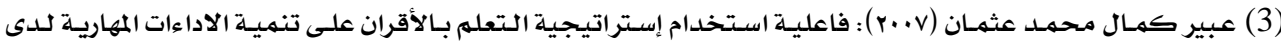

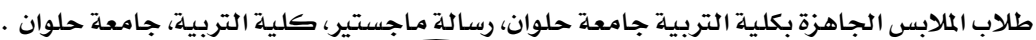


בـ أثراستخدام إستراتيجية تعليم الأقران على إتقان المهارات الفنية للى طلاب قسم التربية الفنية بكلية التريية النوعية لــ

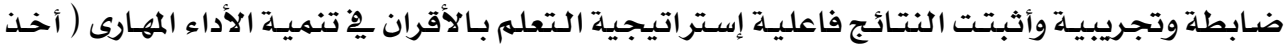
القياسـات ، رسهم وقص وحياكة وتشطيب الملابس ) لدى طالبـات شعبة الملابس.

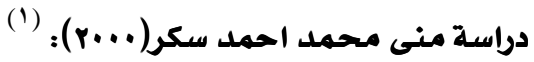

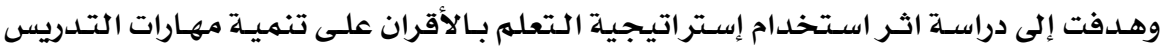

لعينـة بلغت (يץ) مـن الطالبـات المعلمات بـالفرقـة الثالثـة تخصص تربيـة رياضـية بكليـة التربيـة جامعـة

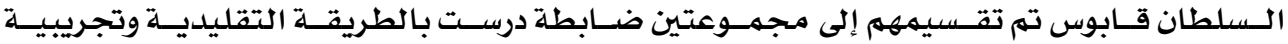
استخدمت إستراتيجية التعلمه بـالأقران وقد أظهرت النتائج بعد تطبيق بطاقة تقييم أداه البحثث تفوق التجريبية على الضابطة يُ مهارات التدريس.

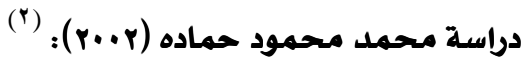
وهدفت إلى دراسـة فاعلية استخدام إستراتيحية التعلمر بالأقران على تنمية مهارات تخطيط وتنفيـذ وتقـويه دروس مـادة الرياضسيات لعينـة مقسـمة إلى مجمـوعتين ضـابطة وتجريبيـة مـن الطلاب

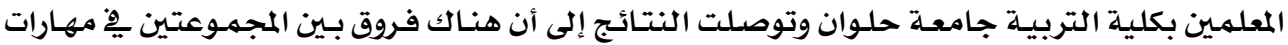
تخطيط وتنفيذ وتقويم دروس مادة الرياضيات لصائ المجموعة التجريبية ووجود علاقة ايجابيـة بـين اكتساب تلك المهارات وأداء العينـة الفعلي يِ المواقف التدريسيـة الفعليـة مهـا أكـد بقـاء اثر التعليهم

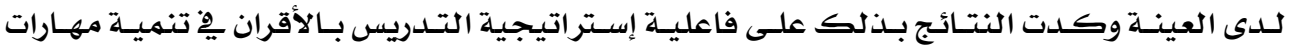
تخطيط وتنفيذ وتقويه دروس مادة الرياضيات وفى انتقال وبقاء أثرها. (") : دراسة (Dochy, Segers \& Sluijsmans, 1999) وهدفت الدراسـة نتيجة للطلب المتزايد على التعلهم مدى الحياة إلى إعادة تقيـيهم العلاقة بـين

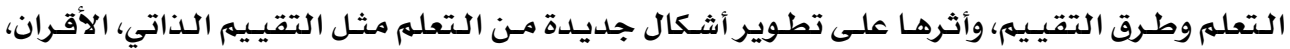
والتقييم المشترك.

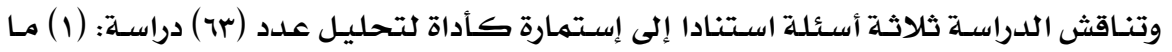
هي النتأُج الرئيسيـة من البحوث حول نهاذج التقييم الجديدة مثل الذاتي، الأقران والتقييهم المشترك (r ) مـا هـي الطريقـة لا يهكن أن تتحقـق النتـائح معـا (r) مـا المبـادئ التوجيهيـة للهـمارسـين التربـويـين يمكن استخخلاصها مـن هذه الهيئحة من المعرفة وأشارت النتائج إلى أن استخدام مزيـج مـن تلك الأشـكال

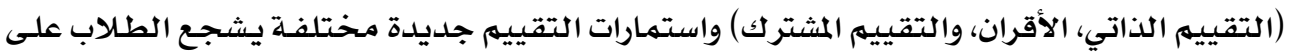

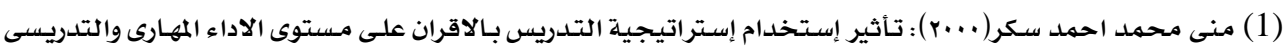

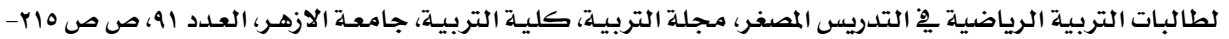

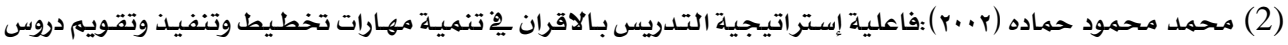

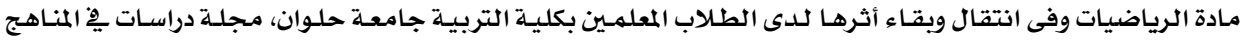

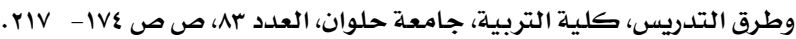

(3) Dochy, F. J. R. C., Segers, M., \& Sluijsmans, D. (1999). The use of self-, peer and coassessment in higher education: A review. Studies in Higher education, 24(3), 331-350. 


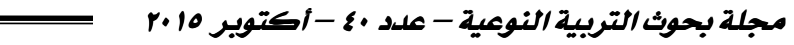

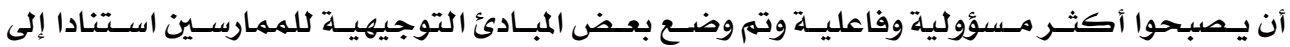
تلك النتائج.

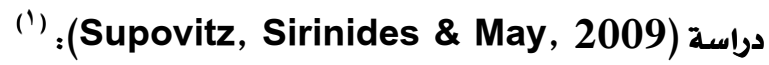

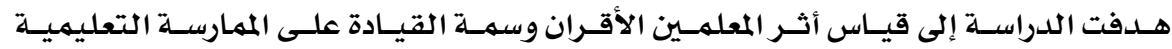

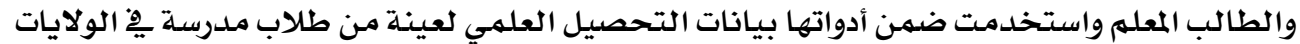

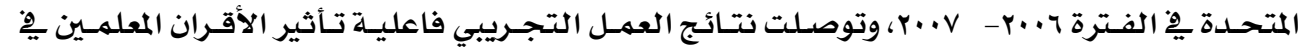

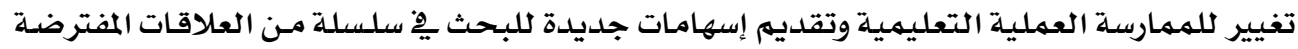

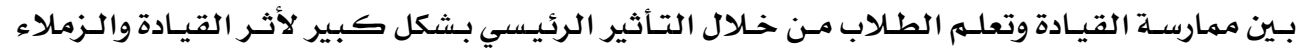

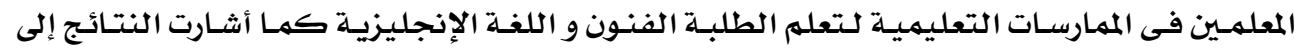

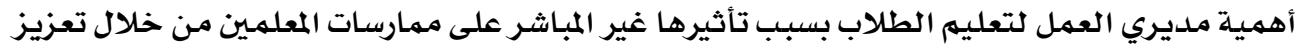
التعاون والتواصل حول التعليمات.

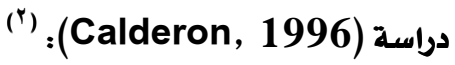

هدفت الدراسـة إلى التعرف على أثر تطبيق إستراتيجية التدريس بـالأقران يِّ تـدريب معلهـي

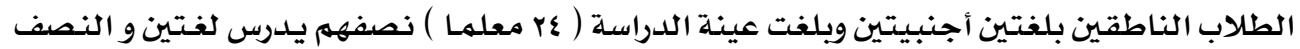

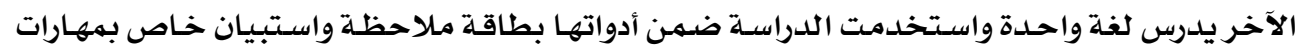

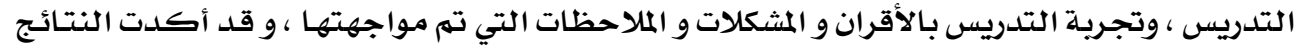

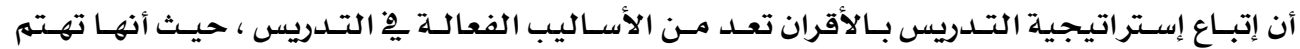

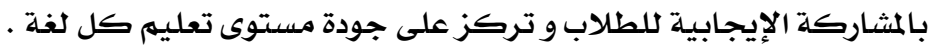

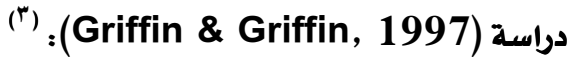

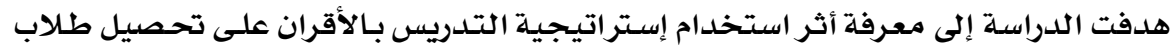

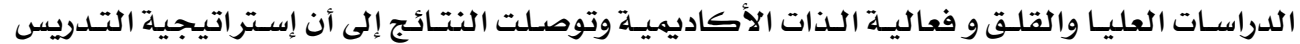

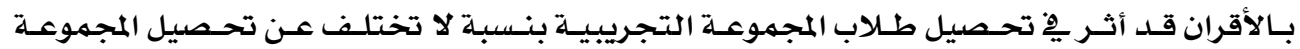

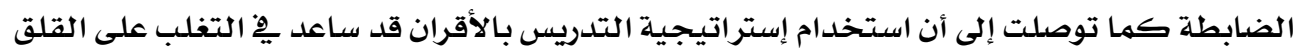

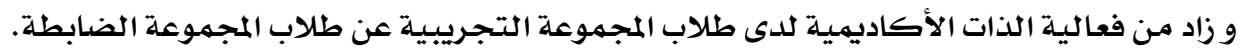

(1)Supovitz, J., Sirinides, P., \& May, H. (2009). How principals and peers influence teaching and learning. Educational Administration Quarterly.

(2) Calderon, M. (1996). How a New Form of Peer Coaching Helps Teachers and Students in Two-Way Bilingual Programs.

http://ieeexplore.iee.. rg/xpl/articleDetails.jsp?arnumber $=6201115$

(3)Griffin, B. W., \& Griffin, M. M. (1997). The effects of reciprocal peer tutoring on graduate students' achievement, test anxiety, and academic self-efficacy. The Journal of experimental education, 65(3), 197-209. 
בب أثراستخلام إستراتيجية تعليم الأقران على إتقان المهارات الفنية للى طلاب قسم التريية الفنية بكلية التربية النوعية لـ

(') دراسة (Marr, 2000):

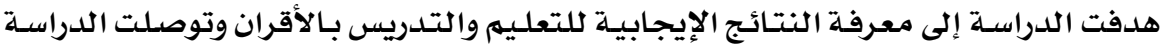

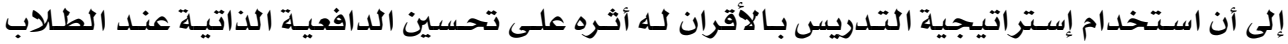

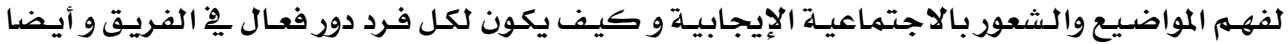

يذكر أفكار تعليمية إضافية " تكنولوجيا متكاملة " .

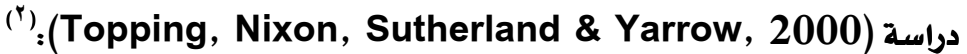

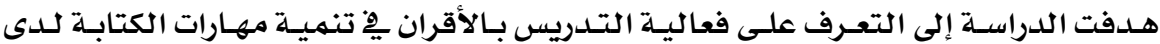

الطلاب المعلمـين و قد توصلت إلى فاعلية التـدريس بـالأقران يف تنـميـة مهارات الكتابـة وهى التخطيط

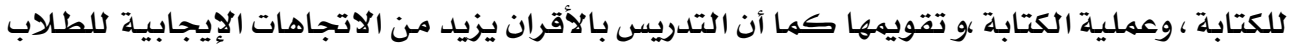

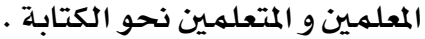

(") (Von der Emde, Schneider \&Kपtter, 2001) دراسة

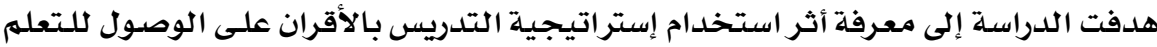

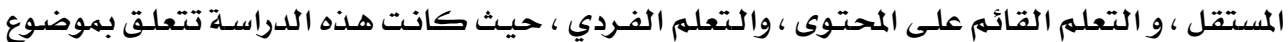

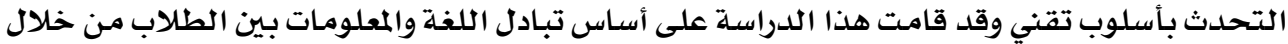

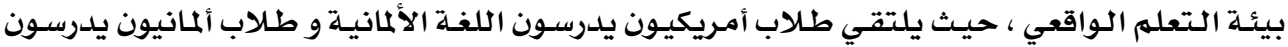

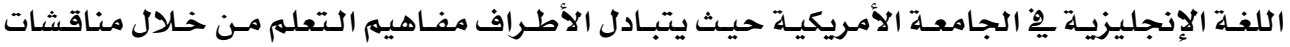

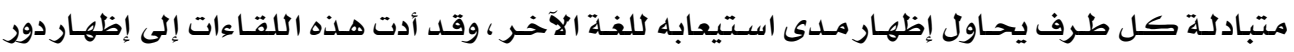

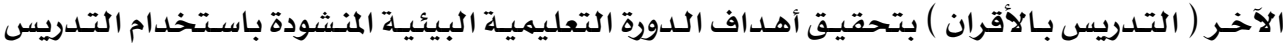

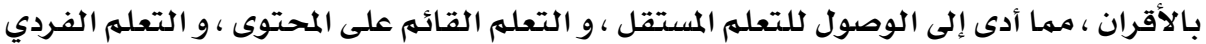

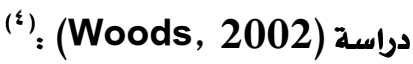

هدفت الدراسـة إلى تقييم فاعلية تثقيف الأقران يِّ تغيير الأثر الاجتماعي السلبي لمتلازمـة

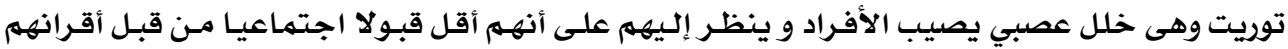

(1)Marr, P. M. (2000). Grouping Students at the Computer to Enhance the Study of British Literature.The English Journal, 90(2), 120-125. doi: 10.2307/821228

(2)Topping, K., Nixon, J., Sutherland, J., \& Yarrow, F. (2000).Paired Writing: A Framework for Effective Collaboration.Reading, 34(2), 79-89. doi: 10.1111/14679345.00139

(3)Von der Emde, S., Schneider, J., \&Kötter, M. (2001). Technically speaking: Transforming language learning through virtual learning environments (MOOs).Modern Language Journal, 210-225.

(4)Woods, D. W. (2002). The effect of video-based peer education on the social acceptability of adults with Tourette's syndrome. Journal of Developmental and Physical Disabilities, 14(1), 51-62. 
بلغت عينـة الدراسـة (r (1) من طلاب الجامعات وأظهرت النتائج أن أفراد المجموعة التجريبيـة أظهروا

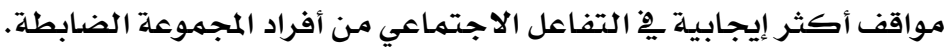
تعقيب على اللدراسات المرتبطة:

استفاد الباحث بعد استعراض ما تقدم من دراسات سابقة التالى :

( ) صيغت فروض البحث بطريقة مباشرة ِِّ ضوء نتائج تلك الدراسات والتى أجمعت على فاعلية

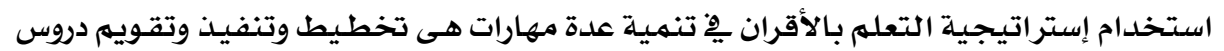

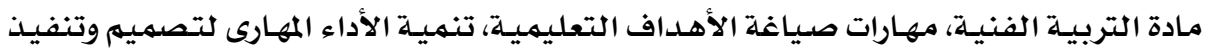

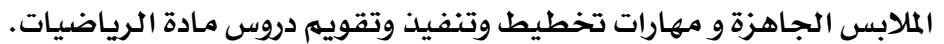

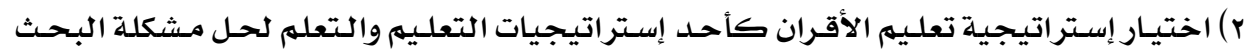

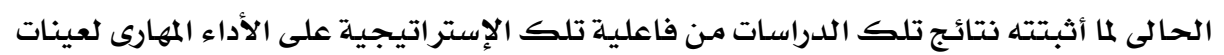

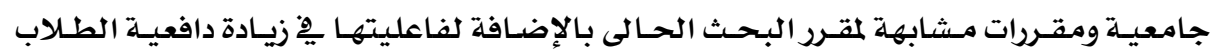

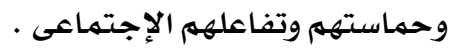

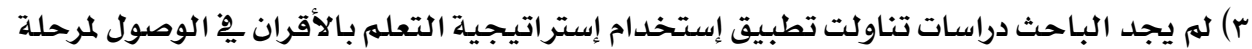

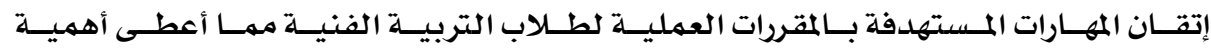

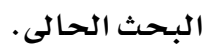

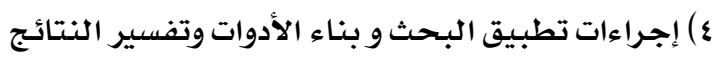
ثانيًا:إجراءات البهث:

\section{تم اتخاذ عدة إجراءات للوصول لأهداف البحث وتتمثل فى :-}

أ. إعداد دليل للطالب / المعلم لتعليم مهارات رسم موضوع الطبيعة الصامتة إعداد الباحث ملحق( (1) :

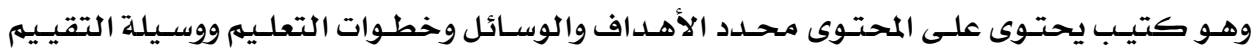

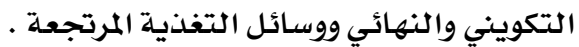

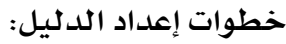

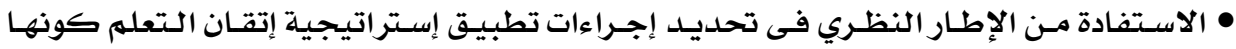
الأساس الفلسفي لبناء دليل تعليم مهارات الرسيم.

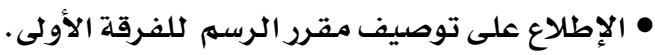

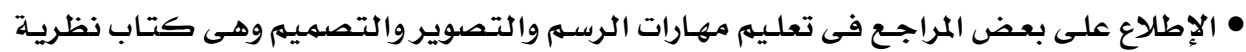

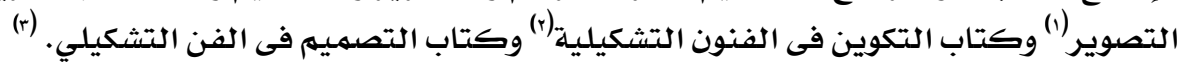

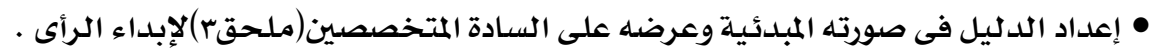

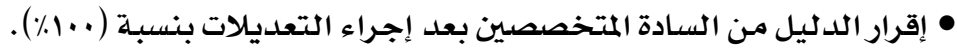


בب أثراستخدام إستراتيجية تعليم الأقران على إتقان المهارات الفنية للى طلاب قسمرالتريية الفنية بكلية التربية النوعية لــ • طباعة الدليل بعدد العينـة وإعداد الوسـائل اللازمة والمواد التعليميـة والبـدائل الخاصسة بالتخذيسة

المرتجعـة البعلدية المصححة.

ب. تحديد منهج البحث: تم إستخدام المنهج التجريبى. ت. تحديد عينة البحث بلغت العينـة الكلية (r7) طالب مقسمـين إلى عدد ( اr) طالب من الذين وصلوا

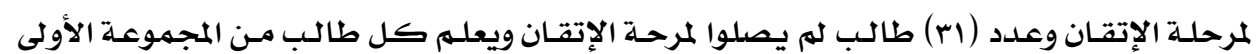

$$
\text { طالب من المجموعة الثانية. }
$$

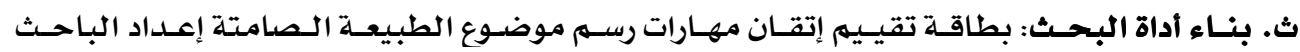

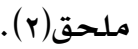

\section{خطوات إعداد بطاقة الثقييه:}

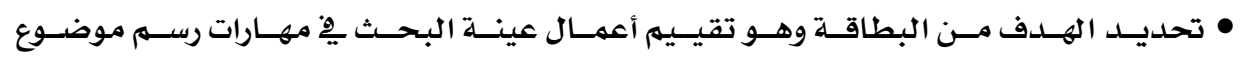

الطبيعة الصامتتة.

$$
\text { • الإطلاع على بعض المقاييس لمهارات الرسهم. }
$$

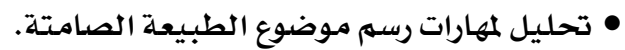

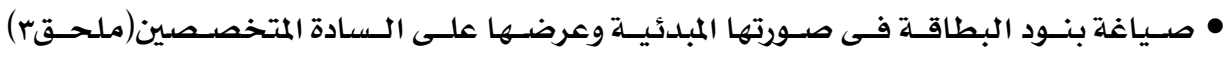

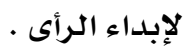

$$
\text { • إقرار البطاقة من السـادة المتخصصين بعد إجراء التعديلات بنسبسة ( . ( ٪). }
$$

حسـاب الصدق والثبـات : تم تقييم المتخصصين (ملحقب) لأعمـال عينـة التقنـين (ن= 10) ثم

تم حسـاب الصدق التكويني لبنود البطاقة بـإستـخدام طريقـة التجـانس الدـاخلي لتلـك البنـود، والـتي تم فيها حسـاب معـامـلات الإرتبـاط بـين درجـة كل عبـارة والدرجـة الكليـة للبطاقـة فكانت جميـع قيم

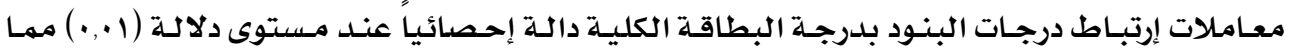

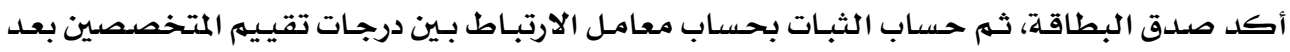

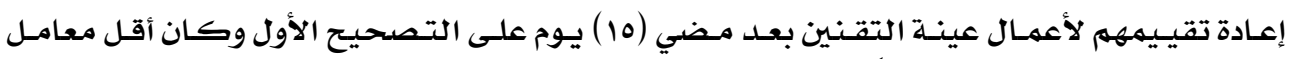

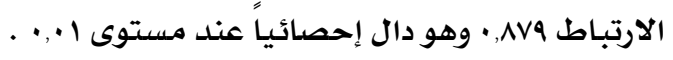

ج· إجراءات تطبيق إستراتيجية تعليه الأقران:

() تعليهم موضوع الطبيعة الصامتة للطلاب وعددهم (Y) ) طالب بأساليب التدريس التقليدي.

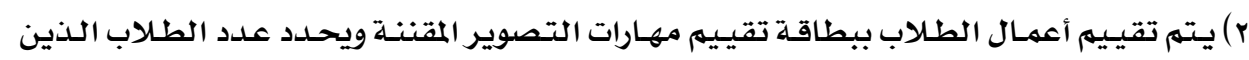

وصلوا لمرحلة الإتقان بعد انتهاء الطلاب من تنفيذ رسمر موضوع الطبيعـة الصامتة.

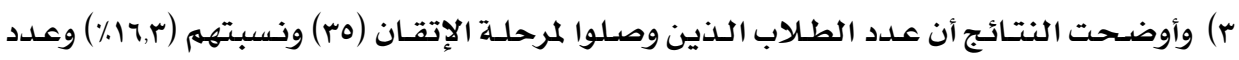

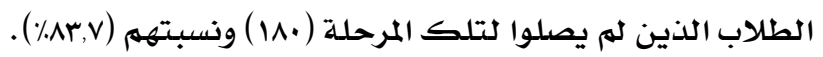

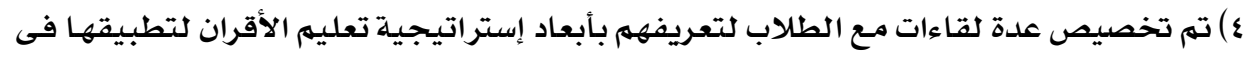

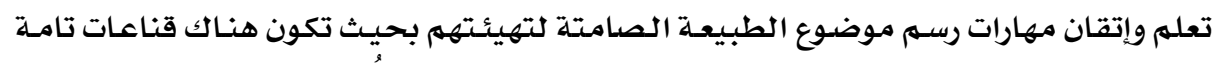
لديهم بالتطبيق لما له من تأثير إيجابى على التجربـة البحثية وفقا للإِطار النظرى بالبحث. 
ه) تم تحديد الطلاب الذين يـودون الاشتراك فى تطبيق إجـراءات البحـث حيث تهـت موافقـة ( اسم)

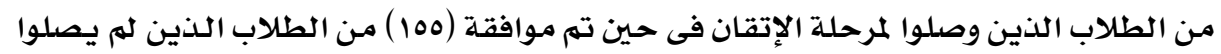

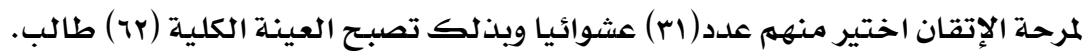

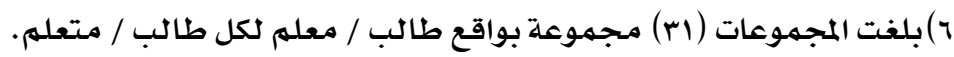

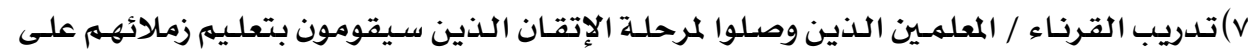

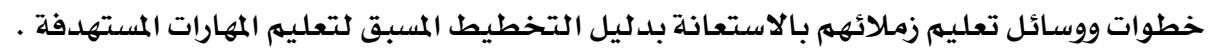

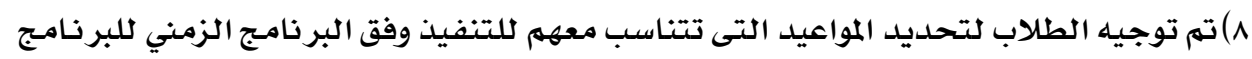
وتقسيم المهارات وترتيبها. ه) قيام القرناء / المعلمـين بتعليهم زملائهمه المهارة الأولى. وتئ. . 1 (1) تقييه تكويني.

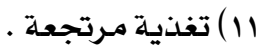

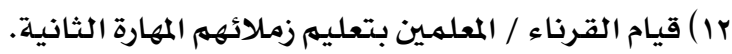

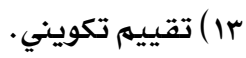

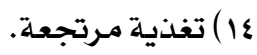
10) قام القرناء / المعلمين بتعليهم زملائهم المهارة الثالثة.

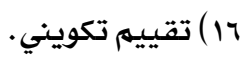

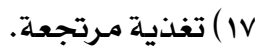

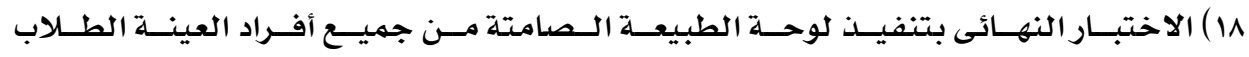

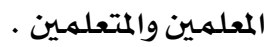

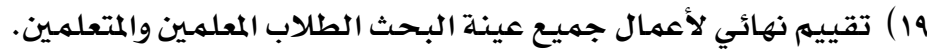

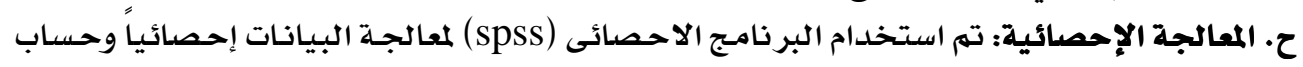

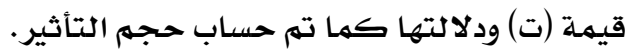

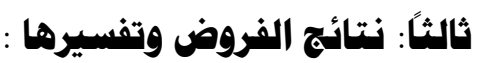

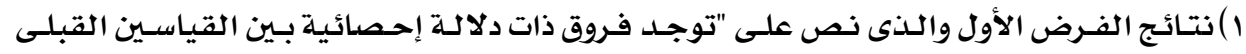

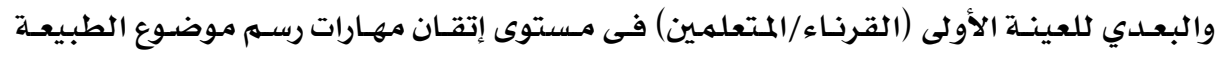

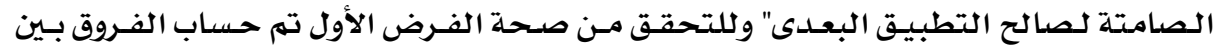

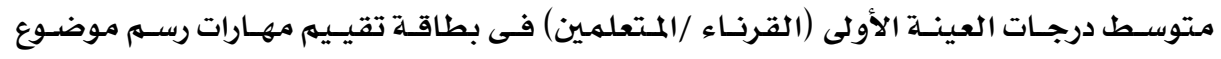

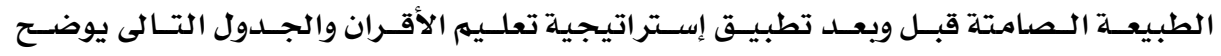

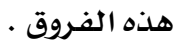




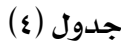

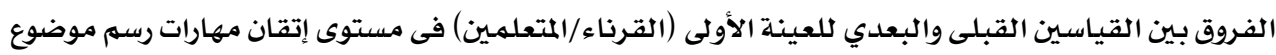
الطبيعة الصامتة

\begin{tabular}{|c|c|c|c|c|c|}
\hline الدلادة & ت & $\varepsilon$ & r & ن & القياس \\
\hline \multirow[t]{2}{*}{$\cdot, \bullet$} & \multirow{2}{*}{$-1 \varepsilon, 7 \cdot 9$} & YI, qVI & V9,17 & \multirow[t]{2}{*}{ r } & القبلى \\
\hline & & YוTו & $\mid Y ৭, \wedge \varepsilon$ & & البعدى \\
\hline
\end{tabular}

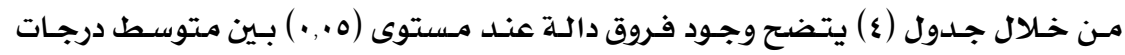

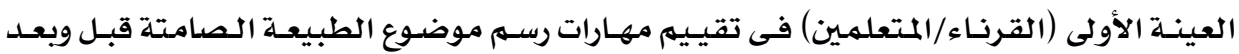

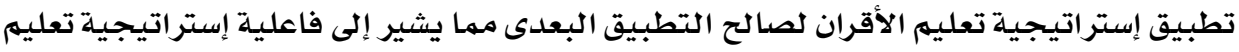

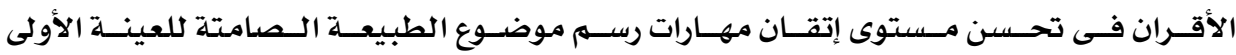
(القرناء /المتعلمـين). حجم التأثير :

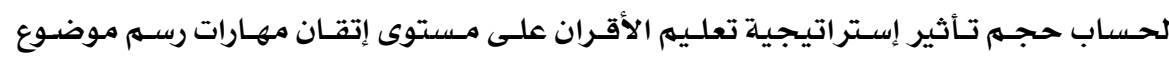

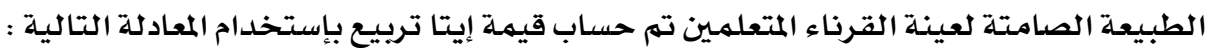

$$
\eta^{2}=\frac{\mathrm{T}^{2}}{\mathrm{~T}^{2}+N-1}
$$

$$
\text { والجدول التالى يوضـح قيمة إيتا تربيع وحجم التأثير }
$$

$$
\text { جدول(0) }
$$

\begin{tabular}{|c|c|c|}
\hline حجم التأثير & $\eta^{2}$ & العينة \\
\hline كبير جدا & $\cdot, \wedge \Lambda$ & القرناء المتعلمـين \\
\hline
\end{tabular}

قيمة إيتا تربيع وحجم التأثير

ويوضح جلدول (ه) أن حجـم تأثير إستراتيجية تعليم الأقران فى تحسين مستوى إتقان

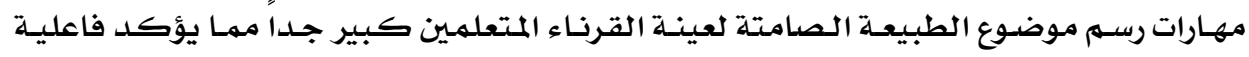
الإستراتيجية التعليميلة.

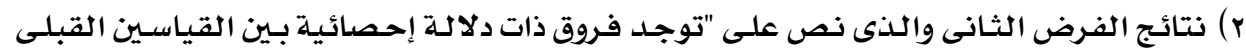

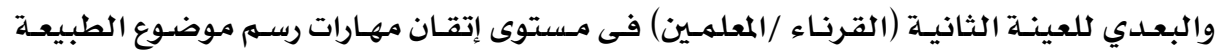

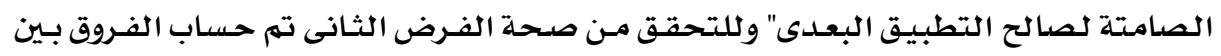

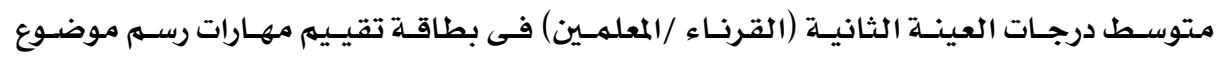

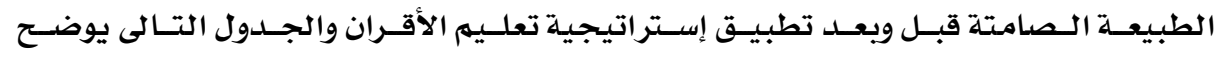

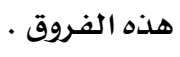




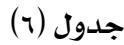

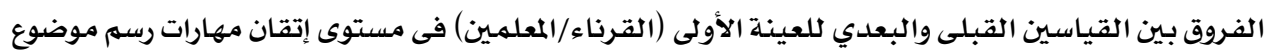
الطبيعة الصامتة

\begin{tabular}{|c|c|c|c|c|c|}
\hline الدلادلة & ت & $\varepsilon$ & r & ن & القياس \\
\hline \multirow[t]{2}{*}{$\cdot, .0$} & \multirow{2}{*}{$-11,700$} & $\Lambda, r \wedge \varepsilon$ & $1 \leqslant \cdot 1$. & \multirow[t]{2}{*}{ r } & القبلى \\
\hline & & $V, 971$ & lor,vr & & البعلدى \\
\hline
\end{tabular}

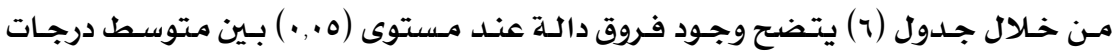

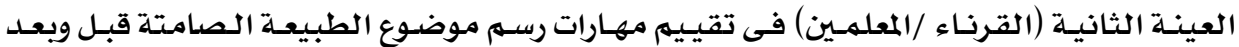

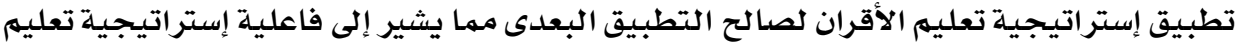

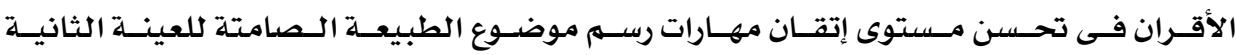
(القرناء /المعلمـين). حجم التأثير :

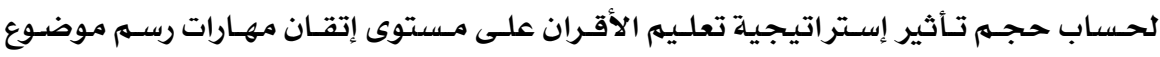
الطبيعة الصامتتة لعينة القرناء المعلمين تم حساب قيمة إيتا تربيع بإستخدام المعادلة التالية :

$$
\eta^{2}=\frac{\mathrm{T}^{2}}{\mathrm{~T}^{2}+N-1}
$$
والجدول التالى يوضح قيمة إيتا تربيع وحجم التأثير

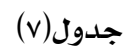

\begin{tabular}{|c|c|c|}
\hline حجم التأثير & $\eta^{2}$ & العينـة \\
\hline كبـير جدا " & $\cdot, \Lambda \Lambda$ & القرناء المعلمـين \\
\hline
\end{tabular}

قيمة إيتا تربيع وحجم التأثير

ويوضح جلدول (v) أن حجم تأثير إستراتيجية تعليم الأقران فى تحسين مستوى إتقان

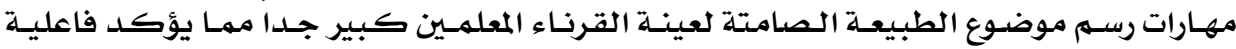
الإستراتيجية التعليمية.

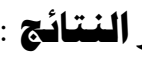

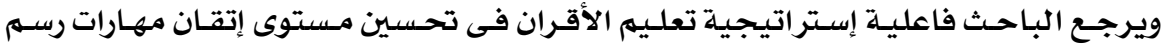

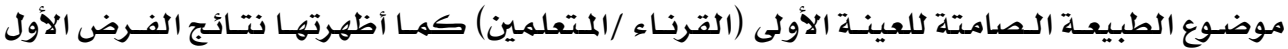

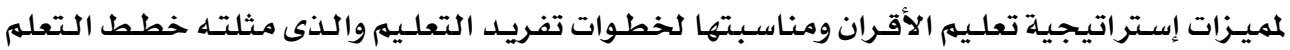

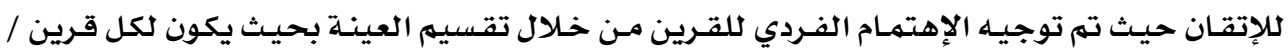


معلهم قرين / متعلهم واحد فقط مهـا أتاح فرصـا أفضل لـه للتعلهم وفقـا لقدرتـه وسـرعته في أداء المهام

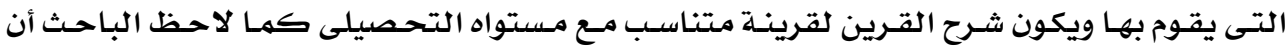

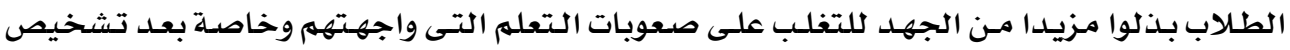

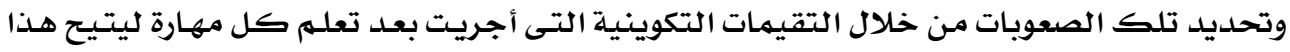

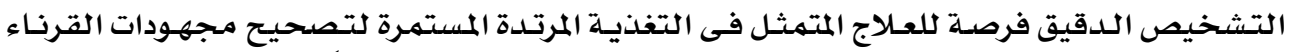

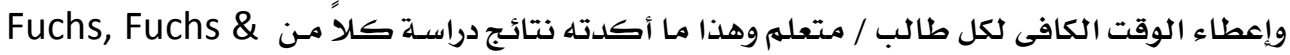

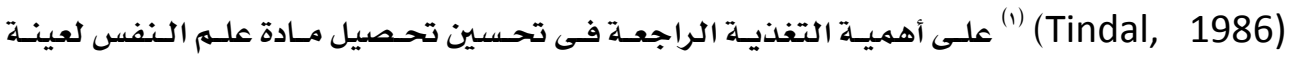

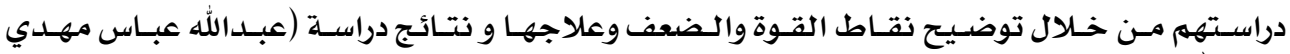

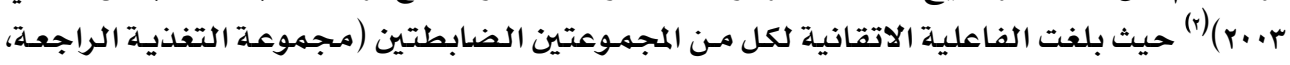

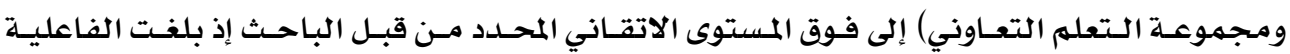

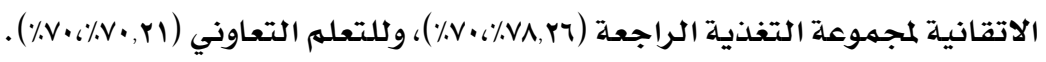

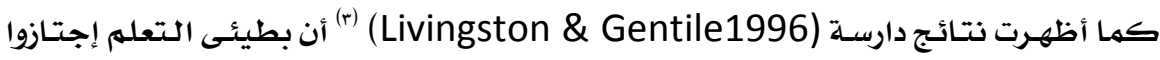

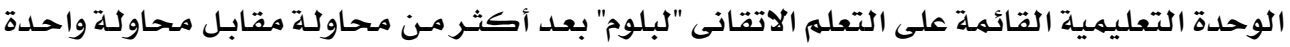

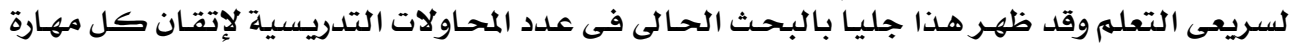

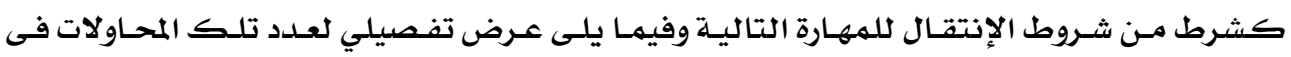
كل مهارة :-

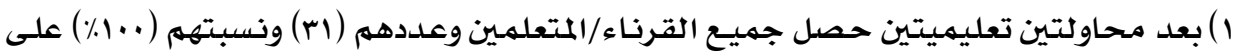

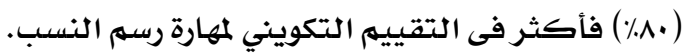

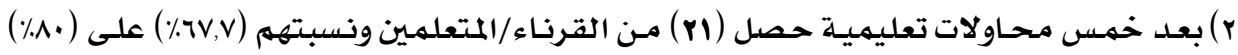

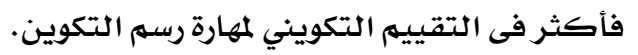

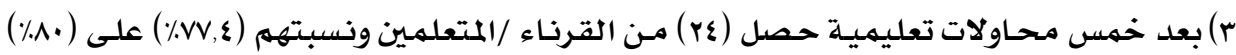

$$
\text { فأكثر فى التقييم التكويني لمهارة التظليل. }
$$

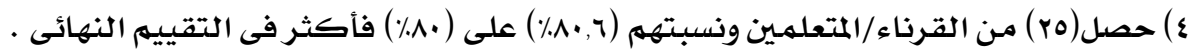

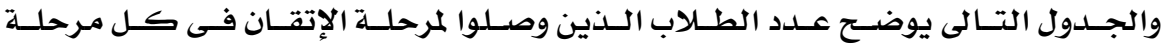

ومهارة بالتفصيل

(1)Fuchs, L. S., Fuchs, D., \& Tindal, G. (1986).Effects of Mastery Learning Procedures on Student Achievement.The Journal of Educational Research, 79(5), 286-291. doi: 10.2307/27540213

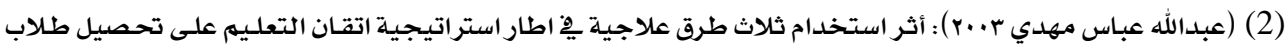

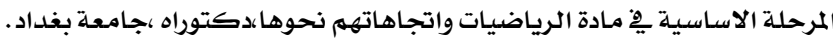

(3)Livingston, J. A., \& Gentile, J. R. (1996).Mastery Learning and the Decreasing Variability Hypothesis.The Journal of Educational Research, 90(2), 67-74. doi: $10.2307 / 27542073$ 
جدول(7)

\begin{tabular}{|c|c|c|c|c|c|c|}
\hline \multirow{3}{*}{ الذين عدد القرناء /المتعلمين } & \multicolumn{5}{|c|}{ عدد القرناء/المتعلمين الذين وصلوا لمرحلة الإتقان بعد كل محاولة تعليمة من أقراتهم } & \\
\hline & المحاولة التعليمية & المحاولة التعليمية & | المحاولة التعليمية & المحاولة التعليمية & | المحاولة التعليمية | & \\
\hline & 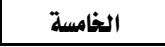 & 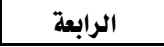 & 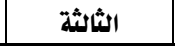 & 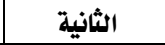 & 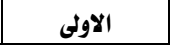 & \\
\hline 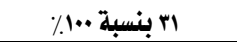 & & & & 7 & ro & مهارة رسم النسب \\
\hline 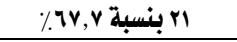 & 1 & $r$ & $r$ & $r$ & ir & مهارة رسم التكوين \\
\hline 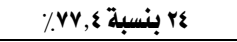 & $r$ & $r$ & $\varepsilon$ & $r$ & ir & 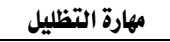 \\
\hline 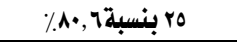 & \multicolumn{6}{|c|}{ علد القرناء/المتعلمين الذين وصلوا لمرحلة الإتقان فى التطبيق النهائى } \\
\hline
\end{tabular}

ورغم عدم وصول ( •9٪) مـن العينـة لمرحلة الإتقان كها حددها "بلوم" و"كلير" إلا أن وصـول

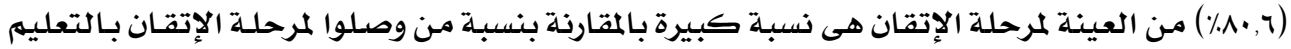

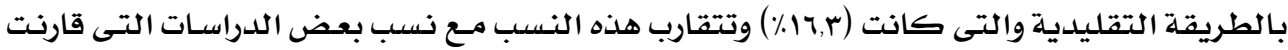

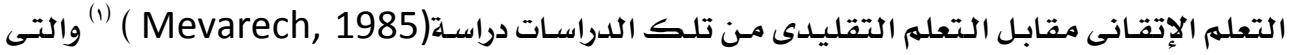

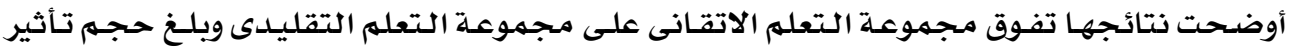

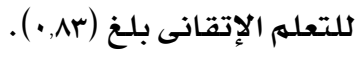

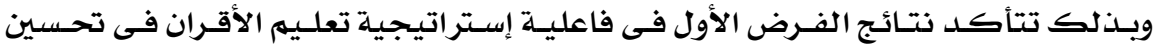

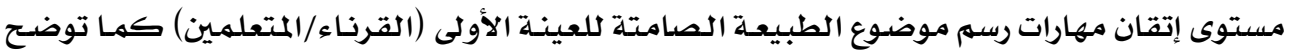

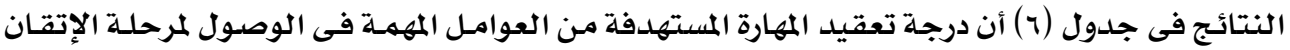

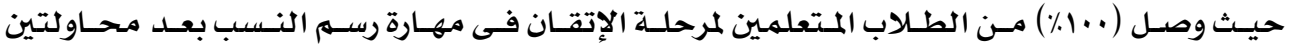

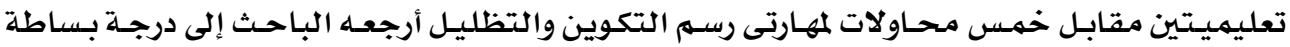
وتعقيد المهارة .

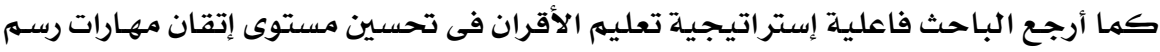

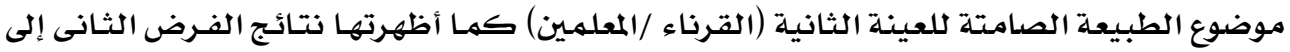

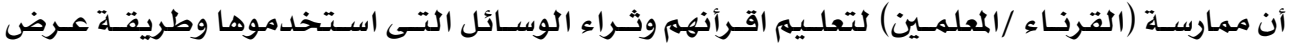

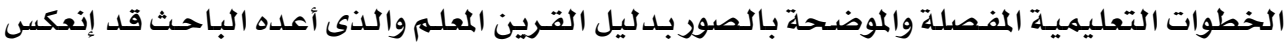
على مستوى أدائهم المهارى. وقـد اتفقـت النتـائج مـع نتـائج الدراسـات المرتبطـة على فاعليـة تعلسيهم الأقـران في تحسـين

$$
\text { مستوى تعلم المهارات المستهدفة. }
$$

(1)Mevarech, Z. R. (1985). The Effects of Cooperative Mastery Learning Strategies on Mathematics Achievement.The Journal of Educational Research, 78(6), 372-377. doi: $10.2307 / 27540154$ 


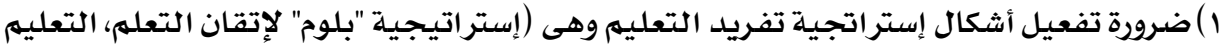

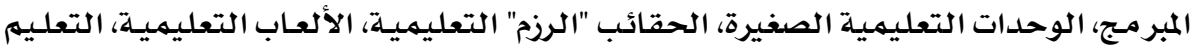

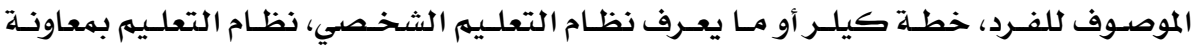

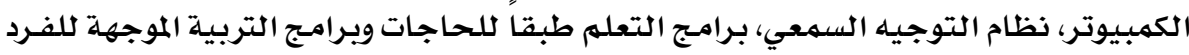

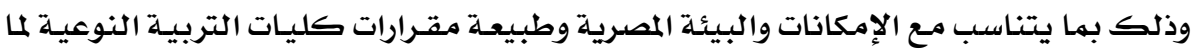

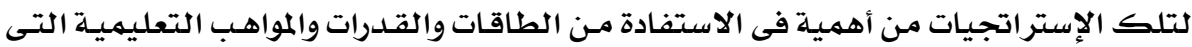

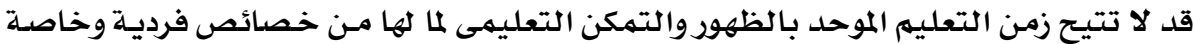

$$
\text { في المقررات العملية. }
$$

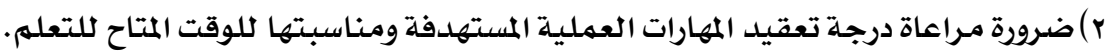

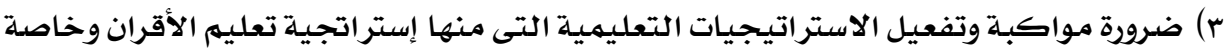

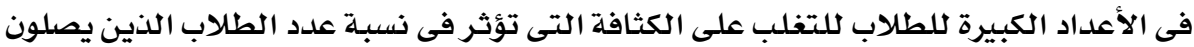

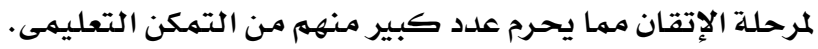

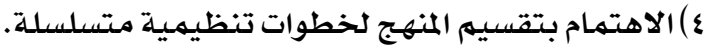

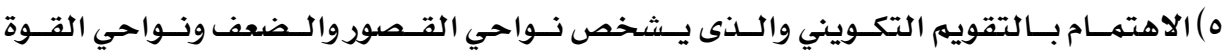
عند الطلاب. 1) الاهتمام بتطبيق التغذية المرتدة العلاجية والتى تعالج نواحي الضعف فى تعليم الطلاب.

1. إبراهيه السيد محمد عطية درويش (1999) . فاعلية استخدام إستراتيجية تـدريس الأقران ِِّ تنمية مهارات

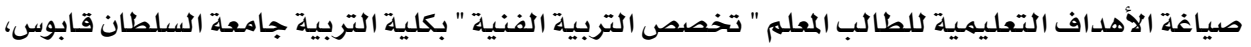

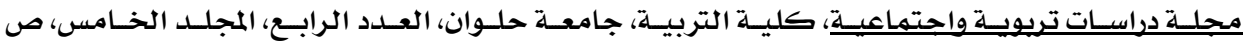
ص\&

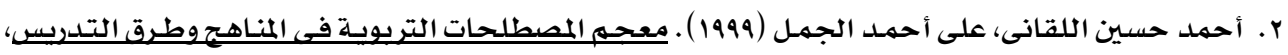

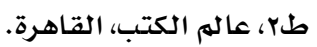
r. أنور محمد الشرقاوي (1991) . التعلمه نظريات وتطبيقات، طه، الانجلو المصرية، القاهرة.

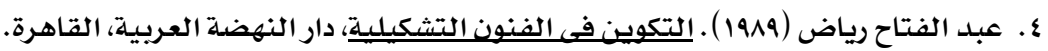

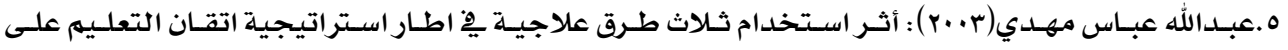

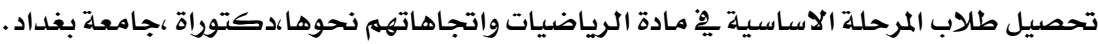

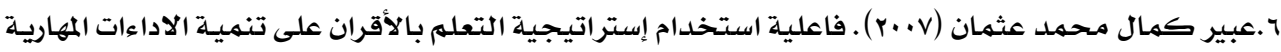

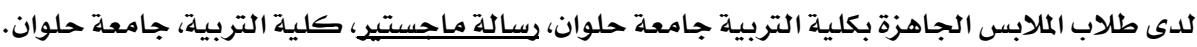




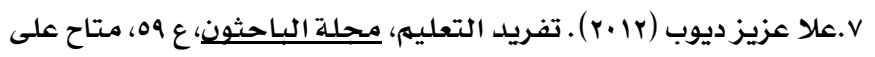

http://albahethon.com/?page=show_det\&select_page=49\&id=1477.^

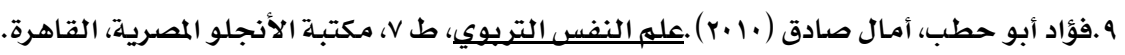

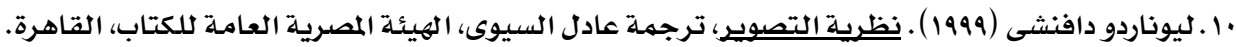

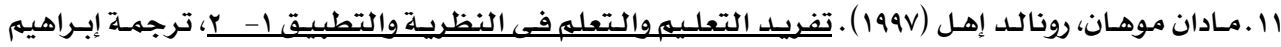

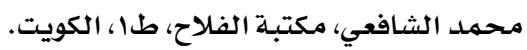

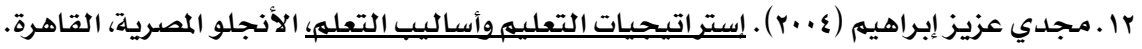

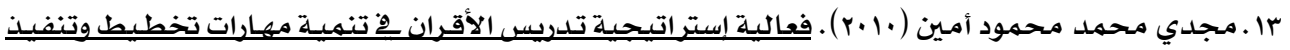

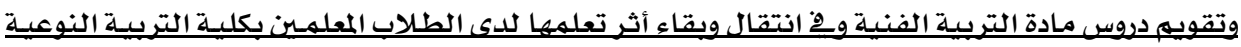

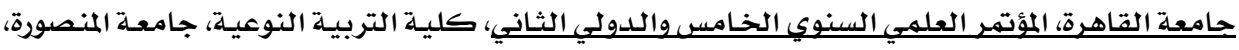

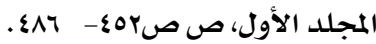

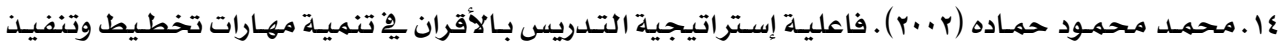

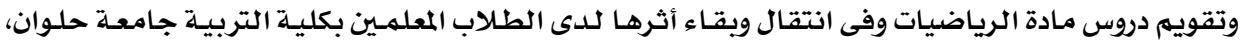

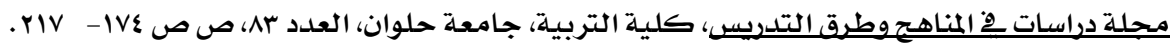

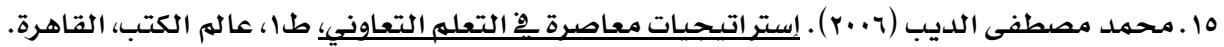

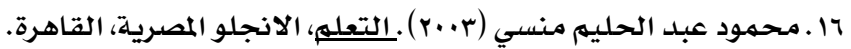

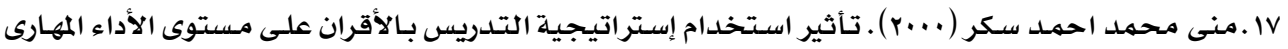

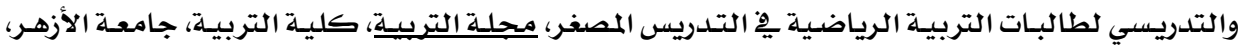

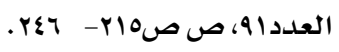

\section{المراجع الأجنبية: - ألمانية}

1. Calderon, M. (1996). How a New Form of Peer Coaching Helps Teachers and Students in Two-Way Bilingual Programs.

2. Damon, W., \& Phelps, E. (1989). Critical distinctions among three approaches to peer education. International journal of educational research, 13(1), 9-19.

3. Dochy, F. J. R. C., Segers, M., \& Sluijsmans, D. (1999). The use of self-, peer and co-assessment in higher education: A review. Studies in Higher education, 24(3), 331-350.

4. Fuchs, L. S., Fuchs, D., \& Tindal, G. (1986).Effects of Mastery Learning Procedures on Student Achievement.The Journal of Educational Research, 79(5), 286-291. doi: 10.2307/27540213

5. Goldschmid, B., \& Goldschmid, M. L. (1976). Peer teaching in higher education: a review. Higher Education, 5(1), p.p 9-33. 
_أثراستخلام إستراتيجية تعليم/الأقران على إتقان المهارات الفنية للى طلاب قسم التريية الفنية بكلية التربية النوعية لــ

6. Griffin, B. W., \& Griffin, M. M. (1997). The effects of reciprocal peer tutoring on graduate students' achievement, test anxiety, and academic self-efficacy. The Journal of experimental education, 65(3), 197-209.

7. Jackson, C. K., \& Bruegmann, E. (2009). Teaching students and teaching each other: The importance of peer learning for teachers (No. w15202). National Bureau of Economic Research.

8. Livingston, J. A., \& Gentile, J. R. (1996).Mastery Learning and the Decreasing Variability Hypothesis.The Journal of Educational Research, 90(2), 67-74. doi: $10.2307 / 27542073$

9. Marr, P. M. (2000). Grouping Students at the Computer to Enhance the Study of British Literature.The English Journal, 90(2), 120-125. doi: 10.2307/821228.

10. Mevarech, Z. R. (1985). The Effects of Cooperative Mastery Learning Strategies on Mathematics Achievement.The Journal of Educational Research, 78(6), 372-377. doi: 10.2307/27540154

11. Sachs, J., \& Parsell, M. (2013). Peer review of learning and teaching in higher education: international perspectives (Vol. 9). Springer Science \& Business Media .

12. Supovitz, J., Sirinides, P., \& May, H. (2009). How principals and peers influence teaching and learning. Educational Administration Quarterly.

13. Topping, K., Nixon, J., Sutherland, J., \& Yarrow, F. (2000).Paired Writing: A Framework for Effective Collaboration.Reading, 34(2), 79-89. doi: 10.1111/1467-9345.00139.

14. Von der Emde, S., Schneider, J., \&Kötter, M. (2001). Technically speaking: Transforming language learning through virtual learning environments (MOOs).Modern Language Journal, 210-225.

15. Woods, D. W. (2002). The effect of video-based peer education on the social acceptability of adults with Tourette's syndrome. Journal of Developmental and Physical Disabilities, 14(1), 51-62. 